\title{
Saving and interest rates in Japan:Why they have fallen and why they will remain low.
}

\author{
R.Anton Braun \\ University of Tokyo \\ Daisuke Ikeda \\ Bank of Japan \\ Douglas H. Joines * \\ University of Southern California
}

August 6, 2004

\begin{abstract}
This paper quantifies the role of alternative shocks in accounting for the recent declines in Japanese saving rates and interest rates and provides some projections about their future course. We consider four distinct sources of variation in saving rates and real interest rates: changes in fertility rates, changes in survival rates, changes in technology and changes in uninsurable labor income risk. The emprical relevance of these factors is explored using a computable dynamic OLG model. We find that the combined effects of demographics and slower total factor productivity growth successfully explain both the levels and the magnitudes of the declines in the saving rate and the after-tax real interest rate during the 1990s. Model simulations indicate that the Japanese savings puzzle is over.
\end{abstract}

*Corresponding author: Marshall School of Business, University of Southern California FBE Dept. Hoffman Hall-701, MC-1427 701 Exposition Blvd. Ste. 701 Los Angeles, CA.90089-1427 email:joines@marshall.usc.edu 


\section{Introduction}

One of the biggest distinctions between Japanese and U.S. households is that the Japanese save more. As recently as 1990 the gap between the personal saving rate in Japan and the United States exceeded 8 percentage points. This gap has spawned a large body of research that has documented these differences and tried to account for the Japanese saving puzzle (see, e.g., Hayashi (1997) and Horioka (1990) for reviews of this literature). Recently this gap has been narrowing. In 2002 the gap had fallen to less than 2 percentage points, leading some to predict that the Japanese saving rate is about to fall below the U.S. saving rate of 4 percent. Associated with this decline in the Japanese personal saving rate has been a concurrent decline in the after-tax real return on capital or after-tax real interest rate, from 6 percent in 1990 to 4 percent in $2000 .^{1}$

This paper quantifies the role of alternative shocks in accounting for the recent declines in Japanese saving rates and interest rates and provides some projections about their future course. We start from the life-cycle hypothesis of Modigliani and Brumberg (1954). This choice is motivated by recent findings of Hayashi (1995) and Horioka, et.al. (2000). Hayashi estimates Engel curves for Japanese households and finds that they are inconsistent with the hypothesis that bequest motives are important. Horioka, et.al. (2000) argue, more generally, that survey evidence of Japanese households is much more consistent with the life-cycle hypothesis than the alternatives of altruistic or dynastic households. Under the life-cycle hypothesis household saving varies with age. With the further assumption of overlapping generations, demographic changes such as the aging of a baby boom can have important implications for saving rates. In order to measure the magnitude of these effects we assume that households live for 65 years. Households are assumed to interact in perfectly competitive markets in a closed, general equilibrium economy. Japan is one of the largest economies in the world both in terms of aggregate and per capita GDP. Japan also has the smallest trade to GDP ratios for both goods and services in the OECD. ${ }^{2}$ For these reasons we think it reasonable to assume that real interest rates are determined in the domestic market in Japan.

We consider four distinct sources of variation in saving rates and real

\footnotetext{
${ }^{1}$ Our measure of the after-tax real interest rate is from Hayashi and Prescott( 2000)

${ }^{2}$ For instance, in 2001 the trade to GDP ratio for goods was $9.3 \%$ in the U.S. and $8.4 \%$ in Japan and the ratio of services to GDP was $2.4 \%$ and $2.3 \%$ respectively
} 
interest rates: changes in fertility rates, changes in survival rates, changes in technology, and changes in uninsurable labor income risk. The interaction of fertility rates and survival rates jointly determines the age distribution of the population at any point in time. By varying fertility rates and survival rates, we can model the effects of a baby boom and increased longevity on the age distribution and thus on aggregate saving rates and interest rates. In a model calibrated to Spanish data, Rios-Rull (2002) found that permanent shocks to demographics have large effects on saving and interest rates.

Changes in unemployment risk can also affect saving and interest rates. In Japan unemployment rates have risen from 2.2 percent in 1990 to 5.5 percent in 2003. The median duration spell of unemployment has also risen from 3.5 months in 1990 to 5.5 months in 2000 and replacement rates have fallen from 0.84 to 0.68 over the same period. From the perspective of Japanese households this represents a big increase in unemployment risk. If this risk is largely uninsurable then households will respond to it by increasing their demand for savings. In addition, the general equilibrium effects described in Aiyagari (1994) imply that real interest rates will also fall.

Finally, changes in the growth rate of productivity can also have large effects on saving and interest rates. Hayashi and Prescott (2002), for instance, have found that the the productivity slow-down in the 1990s produces big declines in after-tax real interest rates in a representative agent real business cycle model.

We calibrate our model to Japanese data and conduct two types of computational experiments. First, we perform a comparative steady-state analysis with a 1990 benchmark. Our goal here is to get a preliminary assessment of the quantitative role of one-time, permanent changes in each of the four factors in explaining the decline in the saving rate and after-tax real interest rate during the 1990s. Second, we conduct a dynamic analysis starting from 1990 to trace out the evolution of saving and interest rates through the middle of the current century under alternative assumptions about productivity and fertility.

In Japanese data after-tax real interest rates fall by about 2 percentage points between 1990 and 2000. Our model produces a decline of 3.8 percentage points in the after-tax real interest rate across steady states. This decline can be decomposed into portions attributable to total factor productivity, unemployment risks, fertility rates and survival rates. When we perform this decomposition we find that declines in the fertility rate and total factor productivity growth have the largest effects. A 1 percentage-point decline in the 
fertility rate, comparable to that in the data, reduces the after-tax real interest rate by about 1 percentage point. A 2 percentage-point decline in total factor productivity growth reduces the after-tax real interest rate by more than 2 percentage points. The magnitude of the other two factors is smaller. An increase in unemployment risk that raises the mean unemployment rate from 2 percent to 5 percent reduces the after-tax real interest rate by only 41 basis points. And a change in survival rates that captures the measured increase in life expectancy between 1990 and 2000 produces a decline in the after-tax real interest rate of only 32 basis points. The steady-state analysis also produces a decline in the net national saving rate.

A limitation of the steady-state analysis is that it can take a long time to transit from one steady state to another. We would really like to know whether the factors we model can individually or jointly reproduce the measured declines in saving rates and interest rates over a ten-year period. To address this question we conduct a dynamic analysis. We abstract from unemployment risk because it is quantitatively small based on the steady-state analysis. Abstracting from unemployment risk also substantially reduces the computational burden. In computing these dynamic simulations we calibrate the demographics to projections made by the National Institute of Population and Social Security Research (IPSS) and posit a gradual recovery of annual total factor productivity growth from 0.3 percent in 2000 to 2 percent in 2010. Under this baseline parameterization we find that the combined effects of demographics and slower total factor productivity growth successfully explain the initial levels, the year-to-year patterns, and the magnitudes of the declines in the saving rate and the after-tax real interest rate during the 1990s.

Given the success of the model in reproducing saving and interest rate patterns in the 1990s it is also interesting to document the model's projections for the future time paths of these two variables. Our long-term simulations indicate that the Japanese saving puzzle is over. In future years the Japanese net national saving rate falls to 2 percent in 2010 and then gradually rises to 3.4 percent in 2024. Projections for the after-tax real interest rate suggest that interest rates have nearly bottomed out and will gradually rise by a total of about 25 basis points over the next twenty years. These forecasts are predicated on a recovery in total factor productivity growth. If instead total factor productivity growth remains low then the saving rate is projected to fall to 0.1 percent and the after-tax real interest rate to about 1.5 percent by 2024. 
Our work is related to research by Hayashi, Ito, and Slemrod (1988), who investigate the role of imperfections in the Japanese housing market in accounting for the Japanese saving puzzle in an overlapping generations endowment economy. They find that the combination of rapid economic growth, demographics, and housing market imperfections explains the level of Japanese saving rates in 1980. Their projections, which condition on an unchanged real interest rate, show declines in the saving rate of about 10 percent between 2000 and 2030 .

The remainder of the paper is divided into five sections. In section 2 we describe the model economy. Section 3 reports the calibration of the model and the steady-state analysis, section 4 reports results of the dynamic analysis and section 5 contains our conclusions.

\section{Model}

\subsection{Demographic Structure}

This economy evolves in discrete time. We will index time by $t$ where $t \in\{\ldots,-2,-1,0,+1,+2, \ldots\}$. Households can live at most $J$ periods and $J$ cohorts of households are alive in any period $t$. They experience mortality risk in each period of their lifetime.

Let $\mu_{j, t}$ denote the number of households of age $j$ in period $t$. Then the dynamics of population are governed by the first-order Markov process:

$$
\mu_{t+1}=\left[\begin{array}{ccccc}
\left(1+n_{1, t}\right) \psi_{1, t} & 0 & 0 & \ldots & 0 \\
\psi_{2, t} & 0 & 0 & \ldots & 0 \\
0 & \psi_{3, t} & 0 & \ldots & 0 \\
\ldots \ldots \ldots & \ldots \ldots \ldots \ldots . \\
0 & 0 & 0 & \psi_{J, t} & 0
\end{array}\right] \mu_{t} \equiv \Gamma_{t} \mu_{t}
$$

where $\mu_{t}$ is a $J \times 1$ vector that describes the population of each cohort in period $t, \psi_{j, t}$ is the conditional probability that a household of age $j-1$ in period $t$ survives to period $t+1$, and $\psi_{1, t}=1$ for all $t$. The growth rate of the number of age- 1 households between periods $t$ and $t+1$ is $n_{1, t}$, which we will henceforth refer to as the net fertility rate. ${ }^{3}$ The aggregate population

\footnotetext{
${ }^{3}$ Note that this usage differs from other common definitions of the fertility rate and that the net fertility rate, as we have defined it, can be negative, indicating a decline in the
} 
in period $t$, denoted by $N_{t}$, is given by

$$
N_{t}=\sum_{j=1}^{J} \mu_{j, t} .
$$

The population growth rate is then given by $n_{t}=N_{t+1} / N_{t}$. The unconditional probability of surviving from birth in period $t-j+1$ to age $j>1$ in period $t$ is:

$$
\pi_{j, t}=\psi_{j, t} \pi_{j-1, t-1}
$$

where $\pi_{1, t-j+1}=1$ for all $t$.

\subsection{Firm's Problem}

Firms combine capital and labor using a Cobb-Douglas constant returns to scale prodution function

$$
Y_{t}=A_{t} K_{t}^{\alpha}\left(h_{t} N_{t}\right)^{1-\alpha}
$$

where $Y_{t}$ is the output which can be used either for consumption or investment, $K_{t}$ is the capital stock, $h_{t}$ is the average efficiency of labor input and $A_{t}$ is total factor productivity. ${ }^{4}$ Total factor productivity grows at the rate $\gamma_{t}=A_{t+1}^{1 /(1-\alpha)} / A_{t}^{1 /(1-\alpha)}$. We will assume that the the market for goods and the markets for the two factor inputs are competitive. Then labor and capital inputs are chosen according to

$$
\begin{aligned}
r_{t} & =\alpha A_{t} K_{t}^{\alpha-1}\left(h_{t} N_{t}\right)^{1-\alpha} \\
w_{t} & =(1-\alpha) A_{t} K_{t}^{\alpha}\left(h_{t} N_{t}\right)^{-\alpha},
\end{aligned}
$$

where $r_{t}$ is the rental rate on capital and $w_{t}$ is the wage rate.

size of the youngest cohort from one period to the next. We compute quantities analogous to $n_{1, t}$ from Japanese data and use these values to parameterize our model. We use our definition of the fertility rate to describe both the model quantities and their empirical counterparts.

${ }^{4}$ As described below, labor efficiency is assumed to vary with age, so that changes in the age distribution of the population alter the average efficiency of the labor force. This effect is measured by $h_{t}$, while changes in efficiency due to technical progress are captured by $A_{t}$. 


\subsection{Household's Problem}

All households have one adult but may have one or more children. The utility function for a household born in period $t$ is given by

$$
U_{t}=\sum_{j=1}^{J} \beta^{j-1} \pi_{j, t+j-1} u\left(c_{j, t+j-1} / \eta_{j}\right),
$$

where $\beta$ is the preference discount rate, $c_{j, t+j-1}$ is total household consumption for a household of age $j$ in period $t+j-1$, and $\eta_{j}$ is the scale of a household of age $j$. This specification of preferences makes it possible for the size of a household to vary with the age of the adult member but imposes the restriction that the distribution of household size, $\left[\eta_{1}, \ldots, \eta_{J}\right]$, remain fixed over time.

Households inelastically supply their endowment of one unit of time but are subject to non-diversifiable employment risk. The employment risk follows a two-state Markov chain. This Markov chain takes on the value of $\bar{s}_{1}=1$ for employed households and $\bar{s}_{2}=0$ for unemployed households. The transition probability matrix is given by

$$
P=\left[\begin{array}{cc}
1-P_{0} & P_{0} \\
1-P_{1} & P_{1}
\end{array}\right]
$$

where the $(k, l)$ element of the matrix $P, P(k, l)$, is $\operatorname{prob}\left(s_{j+1}=\bar{s}_{l} \mid s_{j}=\bar{s}_{k}\right)$. We assume a stationary process so that the unemployment rate denoted by $\nu$ is given by $\nu=P_{0} /\left(1+P_{0}-P_{1}\right)$. Employed workers of age $j$ receive labor income that consists of an efficiency-weighted wage rate $w_{t} \varepsilon_{j}$ in period $t$, and unemployed individuals receive unemployment benefits of $m w_{t} \varepsilon_{j}$. The efficiency index $\varepsilon_{j}$ is assumed to drop to zero for all $j \geq J_{r}$, where $J_{r}$ is the retirement age. The budget constraint for a household of age $j$ in period $t$ is:

$$
c_{j, t}+a_{j, t} \leq R_{t} a_{j-1, t-1}+w_{t} \varepsilon_{j} s_{j}+m w_{t} \varepsilon_{j}\left(1-s_{j}\right)+\xi_{t}-\theta_{j, t}
$$

where $a_{j, t}$ denotes assets held at the end of period $t$ (with $a_{0, t}=0$ for all $t$ ), $\theta_{j, t}$ are taxes on capital income imposed by the government, $\xi_{j, t}$ is a lumpsum government transfer, and $R_{t}=r_{t}+1-\delta$. Households are also subject to a borrowing constraint that rules out negative holdings of assets: $a_{j, t} \geq 0$.

Taxes imposed by the government are given by

$$
\theta_{j, t}=\tau_{a}\left(R_{t}-1\right) a_{j-1, t-1}
$$

where $\tau_{a}$ is the tax rate on capital income. 


\subsection{Household's Decision Rules}

Suppose that a household's asset holdings take on a finite number of values $a \in\{0, \ldots ., \bar{a}\}$. Then we can summarize the situation of an age- $j$ household in period $t$ with the state variable $x_{j, t}$. The individual state consists of asset holdings $a_{j-1, t-1}$ and employment status: $x_{j, t}=\left\{a_{j-1, t-1}, s_{j}\right\}$. The period- $t$ wealth distribution describes the measure of households in each individual state: $\lambda_{j}\left(x_{j, t}\right), j=1, \ldots . J$. Then the aggregate state of the economy, denoted $X_{t}$, is composed of the aggregate capital stock, $K_{t}$, total factor productivity, $A_{t}$, the wealth distribution, $\lambda_{t}$, and the population distribution, $\mu_{t},: X_{t}=$ $\left\{K_{t}, A_{t}, \lambda_{t}, \mu_{t}\right\}$. Finally, define the government policy rule in period $t$ as $\Psi_{t}$. It will be convenient when solving the household's problem to assume that households know the entire future path of government policies: $\Psi^{t}=\left\{\Psi_{i}\right\}_{i=t}^{\infty}$ and the entire future path of total factor productivity. With these various definitions and assumptions in hand, we can now state Bellman's equation for a typical household:

$$
\begin{aligned}
& V_{j, t}\left(x_{j, t} ; X_{t}, \boldsymbol{\Psi}^{t}\right) \\
= & \max \left\{u\left(c_{j, t} / \eta_{j}\right)+\beta \psi_{j+1} \sum_{s_{j+1}} V_{j+1}\left(x_{j+1, t+1} ; X_{t+1}, \Psi^{t+1}\right) P\left(s_{j+1}, s_{j}\right)\right\}
\end{aligned}
$$

subject to

$$
\begin{aligned}
& c_{j, t}+a_{j, t} \leq R\left(X_{t}\right) a_{j-1, t-1}+w\left(X_{t}\right) \varepsilon_{j} s_{j}-\theta_{j, t}+m w\left(X_{t}\right) \varepsilon_{j}\left(1-s_{j}\right)+\xi_{t} \\
& a_{j, t} \geq 0, \quad c_{j, t} \geq 0 \\
& \mu_{t+1}=\Gamma_{t} \mu_{t}
\end{aligned}
$$

and the law of motion of the aggregate wealth distribution and the law of motion for the aggregate capital stock given by $K_{t+1}=K\left(X_{t}\right)$. Since households die at the end of period $J, V_{J+1, t}=0$ for all $t$. A solution to the household's problem consists of a sequence of value functions: $\left\{V_{j, t}\left(x_{j, t} ; X_{t}, \boldsymbol{\Psi}^{t}\right)\right\}_{j=1}^{J}$ for all $t$, and policy functions: $\left\{a_{j, t}\left(x_{j, t} ; X_{t}, \Psi^{t}\right), c_{j, t}\left(x_{j, t} ; X_{t}, \Psi^{t}\right)\right\}_{j=1}^{J}$ for all $t$. The law of motion for the wealth distribution is computed using forward recursion on the following sum:

$$
\lambda_{j+1}\left(x_{j+1, t+1}\right)=\sum_{s} \sum_{a_{j-1, t-1} \in \Lambda_{j, t}} P\left(s_{j}, s_{j+1}\right) \lambda_{j}\left(x_{j, t}\right)
$$


where the set $\Lambda_{j, t}$ is $\left\{a_{j-1, t-1} \mid a_{j, t} \in a_{j, t}\left(x_{j, t}, X_{t} ; \boldsymbol{\Psi}^{t}\right)\right\}$. The recursion starts from the initial conditions of a newly-born household with zero assets:

$$
\begin{aligned}
& \lambda_{0}\left(0, \bar{s}_{1}\right)=1-\nu \\
& \lambda_{0}\left(0, \bar{s}_{2}\right)=\nu
\end{aligned}
$$

and otherwise $\lambda_{0}(\cdot)=0$.

\subsection{Government}

The government raises revenue by taxing capital income at the rate $\tau_{a}$. It receives additional revenue by imposing a 100-percent tax on all accidental bequests. ${ }^{5}$ Total accidental bequests in period $t+1$ are:

$$
B_{t+1}=\sum_{j} \sum_{a} \sum_{s}\left(1-\psi_{j+1, t+1}\right) R\left(X_{t+1}\right) a_{j, t}\left(x_{j, t}\right) \lambda_{j}\left(x_{j, t}\right) \mu_{j, t}
$$

and total tax revenue from capital income taxes is:

$$
T_{t}=\sum_{j} \sum_{a} \sum_{s} \theta_{j, t}\left(x_{j, t}\right) \lambda_{j}\left(x_{j, t}\right) \mu_{j, t}
$$

Note that $\theta_{j, t}$ depends on $x_{j, t}$ since it is a function of $a_{j-1, t-1}$ by (10). Total government expenditure is the sum of unemployment insurance benefits and lump-sum transfers:

$$
G_{t}=\sum_{j} \sum_{a} m w\left(X_{t}\right) \varepsilon_{j} \lambda_{j}\left(x_{j, t} \mid s_{j}=\bar{s}_{2}\right) \mu_{j, t}+\sum_{j} \xi_{t} \mu_{j, t}
$$

\footnotetext{
${ }^{5}$ Our model does not explicitly include labor income taxes, consumption taxes, or government purchases. Ignoring labor income taxes is not restrictive, given the assumption of inelastic labor supply and the presence of lump-sum taxes or transfers. Suppose that government purchases enter household utility functions in an additively separable way, possibly with zero weight. Suppose in addition that these purchases are financed entirely by a flat-rate consumption tax that is constant across the life cycle. Then in a steady state, household asset holdings and gross-of-tax consumption expenditures at each age are independent of the level of government purchases and the consumption tax rate. Given a fixed capital income tax rate, any variation in government purchases not financed by the consumption tax can be financed only by lump-sum taxes. Any effect of such taxes on household saving would be an artifact of assumptions about how they are allocated over the life cycle.
} 
Assume that government expenditure in period $t$ equals period- $t$ government revenue or that the government budget constraint is balanced in each period: $B_{t}+T_{t}=G_{t}$. Then lump-sum transfers are:

$$
\xi_{t}=\left(B_{t}+T_{t}-\sum_{j} \sum_{a} m w\left(X_{t}\right) \varepsilon_{j} \lambda_{j}\left(x_{j, t} \mid s_{j}=\bar{s}_{2}\right) \mu_{j, t}\right) / N_{t}
$$

\subsection{Recursive Competitive Equilibrium}

Given this description of the economy we can now define a recursive competitive equilibrium.

\section{Definition 1: Recursive Competitive Equilibrium}

Given government policy rules $\left\{\boldsymbol{\Psi}^{t}\right\}_{t}$, a law of motion for population $\left\{\Gamma_{t}\right\}_{t}$, a law of motion for unemployment $P$; a recursive competitive equilibrium is a set of value functions $\left\{V_{j, t}\left(x_{j, t} ; X_{t}, \boldsymbol{\Psi}^{t}\right\}_{j=1}^{J}\right.$ for all $t$, policy functions $\left\{a_{j, t}\left(x_{j, t} ; X_{t}, \Psi^{t}\right), c_{j, t}\left(x_{j, t} ; X_{t}, \Psi^{t}\right\}_{j=1}^{J}\right.$ for all $t$, a wealth distribution $\lambda_{t}$, factor prices $\left\{w\left(X_{t}\right), r\left(X_{t}\right)\right\}$ for all $t$, a law of motion for aggregate capital $K_{t+1}=K\left(X_{t}\right)$ and a function for the average efficiency of labor input $h_{t}=h\left(X_{t}\right)$ such that:

- Given the functions of factor prices $\left\{w\left(X_{t}\right), R\left(X_{t}\right)\right\}$ and the law of motion for aggregate capital $K\left(X_{t}\right)$ and the function for average efficiency of labor input $h\left(X_{t}\right)$, the set of household policy functions $\left\{a_{j, t}\left(x_{j, t} ; X_{t}, \Psi^{t}\right), c_{j, t}\left(x_{j, t} ; X_{t}, \Psi^{t}\right)\right\}$ solve the household's dynamic program (11).

- The factor prices are competitively determined so that (5) and (6) hold and $R_{t}=r_{t}+1-\delta$.

- The commodity market clears:

$$
Y_{t}=C_{t}+I_{t}
$$

where $C_{t}=\sum_{j} \sum_{a} \sum_{s} c_{j, t}\left(x_{j, t} ; X_{t}, \mathbf{\Psi}^{t}\right) \lambda_{j}\left(x_{j, t}\right) \mu_{j, t}$ is aggregate consumption and $I_{t}$ is aggregate investment. 
- The laws of motion for aggregate capital and the average efficiency of labor input are given by:

$$
\begin{aligned}
K\left(X_{t}\right) & =\sum_{j} \sum_{a} \sum_{s} a_{j, t}\left(x_{j, t} ; X_{t}, \Psi^{t}\right) \lambda_{j}\left(x_{j, t}\right) \mu_{j, t} \\
h\left(X_{t}\right) & =\sum_{j}^{J_{r}-1} \sum_{a} \epsilon_{j} \lambda\left(x_{j, t} \mid s_{j}=\bar{s}_{1}\right) \mu_{j, t} / N_{t}
\end{aligned}
$$

where $N_{t}=\sum_{j=1}^{J} \mu_{j, t}$.

- The measure of households $\lambda_{t}$ is generated by (15).

- The government budget constraint is satisfied and balanced in each period

$$
B_{t}+T_{t}=G_{t}
$$

In section 3 we perform a comparative steady-state analysis. This analysis is based on the notion of a stationary recursive competitive equilibrium. Before we can define a stationary recursive competitive equilibrium we need to define some of the building blocks.

\section{Definition 2: Stationary population distribution}

Suppose that the fertility rate and the conditional survival probabilities are constant over time: $n_{1, t}=n_{1}$ for all $t$ and $\psi_{j, t}=\psi_{j}$ for all $t$ and $j$. Then a stationary population distribution, $\mu_{t}^{*}$, satisfies $\mu_{t+1}^{*}=\Gamma^{*} \mu_{t}$ and $\mu_{t+1}^{*}=\left(1+n_{1}\right) \cdot \mu_{t}^{*}$ where

$$
\Gamma^{*}=\left[\begin{array}{ccccc}
\left(1+n_{1}\right) \psi_{1} & 0 & 0 & \ldots & 0 \\
\psi_{2} & 0 & 0 & \ldots & 0 \\
0 & \psi_{3} & 0 & \ldots & 0 \\
\ldots \ldots \ldots \ldots \ldots \ldots \ldots & \ldots & \ldots \\
0 & 0 & 0 & \psi_{J} & 0
\end{array}\right]
$$

A stationary population distribution has two desirable properties. First, cohort shares in total population are constant over time: $\mu_{j, t+1} / N_{t+1}=$ $\mu_{j, t} / N_{t}$ for all $t$. Second, the aggregate population growth rate is timeinvariant: $n_{t}=N_{t+1} / N_{t}=n_{1}$ for all $t$. This allows us to convert the growth economy into a stationary economy using the following transformations:

$$
\tilde{c}_{j, t}=\frac{c_{j, t}}{A_{t}^{1 /(1-\alpha)}}, \quad \tilde{a}_{j, t}=\frac{a_{j, t}}{A_{t}^{1 /(1-\alpha)}}
$$


Other per-capita variables in the household budget constraint are transformed in same way. Aggregate variables in period $t$ are transformed by dividing by $A_{t}^{1 /(1-\alpha)} N_{t}$.

\section{Definition 3: Stationary recursive competitive equilibrium}

Suppose the population distribution is stationary and the growth rate of total factor productivity is constant over time: $\gamma_{t}=\gamma^{*}$ for all $t$. Then a stationary recursive competitive equilibrium is a recursive competitive equilibrium that satisfies:

$$
\tilde{c}_{j, t}=\tilde{c}_{j}^{*}, \quad \tilde{a}_{j, t}=\tilde{a}_{j}^{*}
$$

for all $t$ and $j$, i.e., the factor prices are constant over time: $\left\{r_{t}, \tilde{w}_{t}\right\}=$ $\left\{r^{*}, \tilde{w}^{*}\right\}$ for all $t$ where $\tilde{w}=w / A^{1 /(1-\alpha)}$.

This completes the description of the model.

\section{Comparative Steady-state Analysis}

In this section we report results based on comparisons across steady states. We assume that each household has one adult member. New households are formed when individuals reach the age of 21 and households die no later than the end of the 85th year of life. Steady-state comparisons provide a basis for assessing the relative importance of demographics, total factor productivity, and employment risk in the long run.

The model is calibrated to Japanese data. Following Hayashi and Prescott (2002), the capital share parameter $(\alpha)$ is set to 0.36 , the depreciation rate on capital $(\delta)$ is set to 0.089 , and the capital tax rate $\left(\tau_{a}\right)$ is fixed at 0.48 . We assume further that the utility function is isoelastic: $u(c)=\frac{c_{t}^{1-\sigma}}{1-\sigma}$. We choose $\sigma$, the risk aversion coefficent, to be 2 . The preference discount factor is chosen to reproduce the 1990 Japanese after-tax real interest rate of $6 \%$. This yields a value of $\beta=0.97$. The labor efficiency profile is constructed from Japanese data on employment, wages, and weekly hours following the methodology described in Hansen (1993). ${ }^{6}$ Finally, the family scale is calibrated to Japanese data following the methodology of Cubeddu and Rios-Rull (1996).

\footnotetext{
${ }^{6}$ See the data appendix for more details.
} 
We first compute a steady state corresponding to 1990 values of several crucial parameters. In particular, we assume that total factor productivity grows at a constant rate of 2 percent per annum. The transition matrix governing employment status is calibrated to match two data facts: the 1990 unemployment rate of 2 percent and the probability of being unemployed one year conditional on having been employed in the previous year which according to our calculations was 0.069 in 1990 . The annual replacement rate is calibrated to 0.842 to match the length and size of Japanese unemployment benefits. More details on the calculation of the transition probabilities and the replacement rate can be found in the Appendix. The net fertility rate is initially set to a baseline value of 1 percent and mortality risk for each generation is calibrated to Japanese 1990 survival rates. Row 1 of Table 1 reports results for the baseline 1990 steady state.

Row 2 of the table shows a second, hypothetical steady state into which the economy would settle if it were characterized by parameter values that match important features of the Japanese economy as of 2000. This latter calibration assumes an unemployment rate of 5 percent, a conditional probability of being unemployed one year of 0.164 and a lower replacement rate of 0.683 , total factor productivity growth of 0.29 percent, a fertility rate of 0 percent, and 2000 survival rates. ${ }^{7}$

Consider first the interest rate implications of the model. In Japanese data the after-tax real interest rate was 6 percent in 1990 and 3.9 percent in 2000. Comparing the first two rows we see that the model predicts that the after-tax interest rate would fall to a level of 2.03 percent in the new steady state.

\footnotetext{
${ }^{7}$ For total factor productivity growth we took the average value for the $1990 \mathrm{~s}$. Total factor productivity growth exhibits relatively large fluctuations on an annual basis. Taking the average value for the 1990 s smooths out these fluctuations.
} 
Table 1

\begin{tabular}{llcc}
\hline Simulation & $\left(n_{1}, \nu, \gamma, \psi\right)$ & $\hat{r}$ & $\hat{s}$ \\
\hline \hline 1990 baseline & $\left(.01, .02,1.02, \psi^{1990}\right)$ & $6.00 \%$ & $5.32 \%$ \\
2000 baseline & $\left(.00, .05,1.0029, \psi^{2000}\right)$ & $2.03 \%$ & $0.82 \%$ \\
\hline Analysis of 2000 baseline & & & \\
\hline \hline Low fertility rate & $\left(.00, .02,1.02, \psi^{1990}\right)$ & $4.88 \%$ & $3.94 \%$ \\
High unemployment risk & $\left(.01, .05,1.02, \psi^{1990}\right)$ & $5.59 \%$ & $5.53 \%$ \\
Low TFP & $\left(.01, .02,1.0029, \psi^{1990}\right)$ & $3.39 \%$ & $3.02 \%$ \\
2000 mortality & $\left(.01, .02,1.02, \psi^{2000}\right)$ & $5.68 \%$ & $5.48 \%$ \\
\hline
\end{tabular}

Note: $\hat{r}$ is the after-tax real interest rate, denoted by $\left(1-\tau_{a}\right)(r-\delta)$, and the $\psi^{t}$ are the time- $t$ survival rates $\left\{\psi_{j, t}\right\}_{j=1}^{J}$.

Rows 3 through 6 provide information on the contribution of each of the four factors in isolation. According to these results a lower fertility rate and lower total factor productivity growth are the biggest contributing factors. A 1 percentage-point decline in the fertility rate produces a 1.1 percentage point decline in the real interest rate. The reason for this result can be explained as follows. Note first that a lower fertility rate increases the measure of households that are close to retirement age. Since these households also have high wealth, the low-fertility-rate wealth distribution has a higher peak than the high-fertility-rate distribution. With a lower fraction of young workers, aggregate labor input is also lower. Both of these effects raise the capitaloutput ratio and lower the after-tax interest rate.

Slower growth of total factor productivity also increases the capitaloutput ratio and thus lowers the after-tax real interest rate. As Hayashi and Prescott (2002) have previously observed, this effect is quantitatively large during the 1990s. In our simulation a 2 percentage-point decline in total factor productivity growth lowers the steady-state after-tax real interest rate by 2.6 percentage points.

The effects of higher unemployment risk and higher survival rates are much smaller. The combined effects of a higher unemployment rate, longer durations of unemployment and lower replacement rates only reduce the after-tax real interest rate by only 41 basis points. And higher survival probabilities lower the after-tax real interest rate by only 32 basis points.

Consider next the model's implications for saving rates. In Japanese data the national saving rate was 12.8 percent in 1990 and 4.6 percent in $2000{ }^{8}$

\footnotetext{
${ }^{8}$ Our measure of the national saving rate is taken from Hayashi and Prescott (2002).
} 
The model also predicts a decline in saving, but the magnitude of the decline is only half as big as in the data. The two biggest contributing factors are once again lower fertility rates and lower total factor productivity growth. Lower fertility rates contribute about 1.3 percentage points to the decline in the saving rate and lower total factor productivity growth contributes about 2.3 percentage points. Besides understating the decline in the saving rate, the model fails to predict its level in $1990 .^{9}$

Overall, the comparative steady-state analysis finds that both demographics and total factor productivity are quantitatively important determinants of real interest rates. Unemployment risk appears to be much less important. There are several limitations of the steady-state analysis, however. The first is timing. It is not clear whether a dynamic simulation would produce declines of the right magnitudes over a ten-year horizon. A second issue is that it is hard to assert that the Japanese economy was resting at a steady state in 1990. We turn next to conduct a dynamic analysis that addresses these limitations.

\section{Dynamic Analysis}

In this section we report simulation results that model the transitional dynamics. Modeling the transition allows us to describe the full dynamic path for equilibrium quantities and prices in response to changes in fertility and total factor productivity. Our simulations suggest that some big changes in saving rates are in store for the Japanese economy over the next twenty years.

The results in Section 3 indicate that unemployment risk has only a small effect on saving and interest rates. For this reason and also to ease the computational burden of calculating the transitional dynamics, we abstract from unemployment risk in this section.

In order to conduct dynamic simulations it is necessary to specify the entire future time path for the demographic variables and total factor pro-

It is the ratio of net private domestic investment plus the current account surplus to their adjusted measure of GNP.

${ }^{9}$ We will argue below that relaxing the assumption that 1990 was a steady state, and in particular abandoning the steady-state assumption that households were unaware of the coming changes in demographics and productivity growth, results in a saving rate that closely matches the observed 1990 level. 
ductivity. The demographics are pinned down by two sequences, a sequence of net fertility rates $n_{1, t}$ for all future $t$ and the sequence of age-specific survival probabilities $\left\{\psi_{j, t}\right\}_{j=1}^{J}$ for all future $t$. Our baseline parameterization is calculated in the following way. Considering first the demographic variables, for the period 1985 through 2000 we use actual data on fertility rates and survival probabilities. These data are described in more detail in the Appendix. For the period 2000-2050, we choose these two sequences in a way that matches the forecasts produced by the National Institute for Population and Social Security Research (IPSS). Interestingly, we can do a good job of reproducing their forecasts using some very simple assumptions about demographics. Figure 1 reports projections of population shares by the IPSS and our calibrated demographic model. Our projections hold fixed the $\left\{\psi_{j, t}\right\}_{j=1}^{J}$ at their average value for the 1990-2000 period and set the net fertility rate to its 2000 value of -0.1 percent. From these figures it is clear that our calibration does a reasonable job of reproducing the IPSS projections. The most notable difference is that our projections for the fraction of the population aged 66-85 is lower than those of the IPSS from about 2020 on. For the period beyond 2050 we continue to hold the $\left\{\psi_{j, t}\right\}_{j=1}^{J}$ fixed and gradually let the fertility rate rise to zero over a 15 -year period and then hold it constant at this value thereafter. Figure 2 shows the implications of our baseline demographic assumptions for the time path of total population and the time path of fractions of different age groups in total population. This parameterization implies that the Japanese population falls by about 50 percent over the next 100 years.

For total factor productivity we use data from Hayashi and Prescott (2002) for the period 1985 through 2000. Between 2001 and 2010, we assume a gradual increase in the total factor productivity growth rate to 2 percent. Thereafter total factor productivity is assumed to grow at a constant rate of 2 percent per year.

Our dynamic analysis also requires calibration of parameters and starting values for the initial state of the economy, which we take to be 1985 . We continue to use the calibration employed in the steady-state analysis of Section 3, with the exception that the subjective discount factor $\beta$ is adjusted to reproduce the after-tax real interest rate in 1990. This adjustment produces a value of $\beta=0.985$. The aggregate state vector $X_{t}$ consists of the aggregate capital stock, total factor productivity, the age distribution of the population, and total asset holdings of each cohort. The age distribution of the population is taken from Japanese data and total factor productivity 
from Hayashi and Prescott (2002). As we do not have Japanese data on asset holdings by age, we take as our starting point the age-asset profile from our initial steady-state analysis, which we assume applies to 1985.

It is worth emphasizing two points about this initialization. First, it does not matter whether the initial state vector $X_{t}$ corresponds to a steady state. Second, the steady-state analysis is only used to get a starting point for the age-asset distribution, which is then permitted to evolve endogenously beginning in 1985. The other elements of the initial state vector are taken directly or indirectly from Japanese data in $1985 .{ }^{10}$

Figures 3 and 4 report our baseline results. The upper panel of each figure shows the response of the after-tax real interest rate and the lower panel shows the response of the national saving rate. The only difference between Figure 3 and 4 is the dating. Figure 3 focuses on the 1990s while Figure 4 shows long-run projections.

Consider first the 1990s. The model successfully matches the initial level of the after-tax interest rate and the saving rate in the data and shows declines in both variables during the decade. While the model is calibrated to match the 1990 level of the after-tax interest rate, it is not constrained to match the saving rate. The saving pattern in our baseline dynamic analysis is quite different from the steady-state results reported in Section 3. In the comparative steady-state analysis we found that saving rates were low and did not vary much across steady states. The saving rate in the 1990 steady state of Table 1 is only 5.32 percent, whereas our dynamic analysis produces a 1990 saving rate of 11.4 percent, which is close to the observed value. This difference arises because households in the steady-state analysis believe that the steady-state patterns of demographics and total factor productivity growth will persist forever, whereas households at the beginning of the dynamic analysis realize that the initial demographics and productivity growth rate are not at their steady-state levels and will change over time. We

\footnotetext{
${ }^{10}$ Alternatively, it is possible to interpret our dynamic analysis as starting from an initial steady state. Under this interpretation, the steady state is somewhat special in that all economic agents believe that the prevailing age distribution of the population and productivity growth rate will persist indefinitely. Then households and firms wake up to discover that their assumptions about future variables are wrong and instead they will be subject to the sequence of total factor productivities and demographics described above. The simulations then follow household responses to these sequences of exogenous variables until the economy settles down in a new steady state. This is the same assumption made by Rios-Rull (2002) and Nishiyama (2002).
} 
prefer the latter assumption both because it seems more reasonable a priori and also because it more successfully reproduces the observed behavior of the saving rate.

These differences in beliefs affect behavior not only in 1990 but in subsequent years as well. Lower predicted productivity growth and changed demographics cause households to save more at the 1990 interest rate of 6 percent than was the case in the steady-state analysis. Over time, the higher saving rate implies a higher capital stock and lower market interest rates. Lower total factor productivity reinforces the decline in the interest rate. The simulated interest rate series in Figure 3 is almost identical to the empirical series through the first half of the 1990s but is somewhat below the actual during the second half of the decade. The simulated saving rate falls more slowly than the actual series and takes an additional three years to reach the values observed for 1999 and 2000. On the whole though, demographic changes and slower total factor productivity growth can account for most of the decline in Japanese saving and interest rates during the 1990s.

Given the success of our model in reproducing the 1990s, it is also interesting to explore its implications for the future. In this regard, the single most important fact about Japanese saving in the post-World War II period has been its magnitude. Our results indicate that the Japanese saving puzzle is a historical artifact. The results reported in Figure 4 predict that Japan's net saving rate will never exceed 10 percent again. Saving rates fall to a low of 1.5 percent in 2017 and then gradually rise to 3.1 percent by the year 2100. It is worth pointing out that this pattern is driven by persistent but transient shocks to demographics and total factor productivity. Below, we will show that the declines in saving and interest rates are even larger if the shock to total factor productivity growth is assumed to be permanent.

Hayashi, et.al., (1988) also provide long-run projections for saving rates. Their model predicts a decline in the saving rate of 10 percentage points between 2000 and 2030. In our model the saving rate declines by roughly the same amount. The decline in our model is concentrated in the period between 1990 and and 2010, however. Moreover, their projections are conditioned on a very different macroeconomic environment with a constant real interest rate and annual growth rates of output of 4 percent per year.

The baseline results in Figure 4 suggest further that after-tax real interest rates have temporarily bottomed out. They reach a minimum value of 3.1 percent in 2008 and then gradually rise to 3.49 percent in 2024. After that they decline again as the shadow baby-boom generation ages. Currently it is 
estimated that Japanese life insurance companies are experiencing negative spreads on as much as 70 percent of all outstanding life insurance policies (see Nikkei Weekly August 25, 2003). Our projections suggest that it would be a mistake to place a bet on significantly higher future real interest rates.

What is the contribution of total factor productivity and demographic factors to these results? In order to answer this question we report two other simulations in Figure 5. In addition to reproducing our baseline results, the figure reports results that isolate the effects of demographics by holding fixed the growth rate of TFP at 2 percent in all periods. The figure also reports results which hold the demographic pattern fixed at its 1990 level and allow TFP to vary as in the baseline parameterization. Consider first the results for demographics only. Abstracting from changes in total factor productivity growth affects the timing of the declines in the after-tax interest rate and the saving rate but does not affect the peak responses of these variables. The after-tax real interest rate falls to a level of 2.9 percent in 2044 and the saving rate falls to a minimum value of 1.5 percent in 2052 .

From Figure 5 we see that declining total factor productivity by itself produces sharp drops in the saving rate and the after-tax real interest rate in the 1990s, but these responses damp as total factor productivity growth returns to 2 percent in subsequent periods. The magnitude of these declines is also quite a bit smaller than those reported in the baseline parameterization. Here the interest rate falls from 6.7 percent in 1990 to 4.9 percent in 2000 and the saving rate falls from 6.9 percent to 3.4 percent or a total of 3.5 percentage points.

From this we see that both changing demographics and lower productivity growth contribute to reproducing the observed decline in the interest rate from 6 percent in 1990 to 3.6 percent by the year 2000. Lower TFP growth has the bigger contribution during this period but appealing to both factors is important for reproducing the measured declines in interest and saving rates during the $1990 \mathrm{~s}$.

These results also indicate that observed and projected changes in fertility rates produce very persistent responses in the saving rate and the after-tax real interest rate. Sustained but temporary shocks to total factor productivity growth, in contrast, have large contemporaneous effects but do not produce much propagation over time in the model.

Underlying the baseline results is an assumption that the current patterns of total factor productivity growth and demographics are persistent but transient departures from their previous values. TFP gradually recovers 
to 2 percent annualized growth between 2000 and 2010 and the net fertility rate gradually returns to zero after 2050. The results would look very different if the current low growth rate of TFP is assumed to be permanent. Figure 6 reports results for a simulation in which TFP growth is assumed to remain permanently at its 1990s average value of 0.29 percent after 2000 while the fertility rate is set to its baseline values. The assumption of permanently low total factor productivity growth is also maintained by Hayashi and Prescott (2002).

Consider first the real interest rate. This plot has three noteworthy features. First, observe that the recovery of real interest rates after 2004 that occurs under the baseline parameterization in Figure 6 is predicated on a recovery of total factor productivity growth. If instead total factory productivity growth remains low, the real interest rate continues to decline until about 2050. Second, permanently low productivity growth implies that the bottom of the trough is much lower than under the baseline scenario. Here the real interest rate falls to about 1 percent whereas in the baseline specification it only falls to about 2.7 percent. Third, the new steady-state interest rate is also lower. The final steady-state value in Figure 6 for the case of permanently low total factor productivity growth is 1.8 percent or about 2.4 percentage points lower than the baseline specification.

We see similar patterns in the saving rate. The decline in the saving rate is also very large now, falling to -3.5 percent as compared to 1.5 percent for the baseline specification. In addition, the new steady-state saving rate is lower, 0.84 percent here as compared to 4.2 percent for the baseline specification.

These results illustrate that our baseline assumption of a recovery in TFP growth to 2 percent between 2001 and 2010, attenuates the downward pressure on the saving rate and the interest rate coming from the aging of the Japanese population after 2000. Instead, if total factor productivity growth remains permanently low, saving and real interest rates experience even larger and more persistent declines in future years. This raises an interesting question. How strong of a recovery in TFP growth would be needed to offset the forces of an aging population on the Japanese saving rate? One answer to this question is provided by looking at the final steady state. If, for instance, long-run if TFP growth is 15 percent per year and population growth is zero, net investment in the final steady state is 9.6 percent. This value of the saving rate is close to its level in the early 1990s and much higher than the value of 0.84 percent reported in Figure 6 . However, we find it hard to justify steady growth of TFP at rates at such a high rate. Using our dynamic 
analysis we can also investigate what happens over shorter horizons. This is accomplished by producing simulations in which we assume that between 2001 and 2010 TFP growth increases in a linear fashion from 0 percent per annum to alternatively 5 percent, 10 percent and 15 percent per annum. With a recovery to 5 percent TFP growth the saving rate remains below 5 percent until 2022. With a recovery to 10 percent TFP growth the saving rate remains below 5 percent until 2018 and with a recovery to 15 percent TFP growth the saving rate remains below 5 percent until 2016. Based on these results we conclude that Japan's saving rate will remain low for at least the next ten years.

\section{Conclusion}

In this paper we have shown that the measured declines in saving rates and real interest rates in Japan during the 1990s are consistent with the predictions of theory. Both low total factor productivity growth and the life cycle hypothesis play important roles in accounting for these facts. Our theory also has sharp implications for the future evolution of saving rates and interest rates. It provides a quantitative confirmation of previous claims that the Japanese saving puzzle is over. According to our theory, Japanese savings rates will remain below 5 percent for the next ten years and never again exceed 10 percent. Moreover, these projections are reasonably robust. The population distribution, which is a key determinant of savings, changes only gradually over time in a highly predictable way. Thus, even when we posit a robust recovery in total factor productivity, saving rates remain low by historical standards.

Our model could be extended in a variety of ways. It could be adapted to examine whether the high saving rates that Japan experienced in the 1970s can also be explained. It could be generalized to allow for a household labor supply decision. One property of our model is that wages are rising. With endogenous labor supply, participation rates of family members are likely to increase. This increase in family labor supply has interesting implications for, among other things, the sustainability of the Japanese social security system. The model could also be adapted to include a bequest motive. Inheritance tax rates in Japan are high and very progressive. A model with a bequest motive would permit us to investigate the implications of changes in inheritance taxes on bequests. 


\section{Appendix}

\section{A.1 Data set}

\section{Efficiency units by age}

We construct efficiency units by age from time-series data that covers the period from 1990 to 2000 following the methodology of Hansen(1993). For each year an $(11 \times 2)$ age-sex array of data is available. Each of the 22 groups in the array is denoted by subscript $i$ in each year $t .{ }^{11}$

- MEFT: Monthly contractual earnings for employed full-time wage and salary workers

- HEPT: Hourly scheduled cash earnings for part-time wage and salary workers

- AEFT: Annual special cash earnings for employed full-time wage and salary workers ${ }^{12}$

- AEPT: Annual special cash earnings for employed part-time wage and salary workers

- NFT : Number of wage and salary workers who work full-time

- NPT : Number of wage and salary workers who work part-time

- HFT : Monthly actual numebr of scheduled hours worked for employed full-time wage and salary workers

- HPT : Daily actual number of scheduled hours worked for employed part-time wage and salary workers

- NDPT: Monthly Actual number of days worked for employed parttime wage and salary workers

\footnotetext{
${ }^{11}$ The data source is Basic Survey in Wage Structure by the Ministry of Health, Labor and Welfare.

${ }^{12}$ The annual special cash earnings, $A E F T$ and $A E P T$, are reported for the previous year e.g. special cash earnings for 1990 refer to earnings received in 1989. For this reason we treat the annual special cash earnings reported at $t+1$ as those in $t$.
} 
- OHFT: Monthly actual number of overtime hours worked for employed full-time wage and salary workers

- Age : Average age of the each age group

Following Hansen(1993), let small letters denote the real values defined as $x=X / P$ for any nominal variable $X$, where $P$ is the GDP deflator. From the data series obtained in above we can construct the following series:

- weft: Average weekly earnings for employed full-time wage and salary workers

- wept: Average weekly earnings for employed part-time wage and salary workers

- AHFT: Average weekly hours for employed full-time wage and salary workers

- AHPT: Average weekly hours for employed part-time wage and salary workers

where

$$
\begin{aligned}
& \text { weft }=\text { meft } / 4+\text { aeft } / 48 \\
& \text { wept }=\text { hept } \cdot H P T \cdot N D P T / 4+\text { aept } / 48 \\
& A H F T=(H F T+O H F T) / 4 \\
& A H P T=H P T \cdot N D P T / 4
\end{aligned}
$$

From these data an weekly measure of hourly earnings for each subgroup at time $t\left(H E_{i t}\right)$ was constructed as:

$$
H E_{i t}=\frac{w e f t_{i t} \cdot N F T_{i t}+w_{e p t} \cdot N P T_{i t}}{A H F T_{i t} \cdot N F T_{i t}+A H P T_{i t} \cdot N P T_{i t}}
$$

Let $H E_{i}$ be the average of $H E_{i t}$ over the $t$-year sample. The efficiency units for each age-sex subgroup $i$ are formed as follows:

$$
\epsilon_{i}=H E_{i} / H E
$$

where

$$
H E=\frac{\sum\left(N F T_{i}+N P T_{i}\right) H E_{i}}{\sum\left(N F T_{i}+N P T_{i}\right)}
$$


where $N F T_{i}$ and $N P T_{i}$ are average over $t$. We next construct, $\epsilon$, an $(11 \times 1$ vector) of efficiency units by age. Each element of this vector is a weighted average of the $\epsilon_{i}$ 's for males and females in that age group, where the weights are the numbers of male and female workers. From these 11 values we derive the $\epsilon_{j}$ for each age $j=21, \ldots, 65$ using interpolation by polynomials.

\section{Replacement rate}

Our model is an annual one, whereas most of the Japanese regulations and data relating to unemployment are categorized in terms of unemployment duration measured in months. For example, an employed person who loses his/her job gets at most 3 months of unemployment benefits. The nominal replacement ratio varies between $50 \%$ to $80 \%$ depending on the age and the salary of the person as prescribed by the Social Security Law. We define the model's nominal replacement ratio as $\bar{m}=0.65$.

Define, $p_{0}$ to be the probability of becoming unemployed in any month given that one was employed the previous month and let $p_{i}$ be the probability of being unemloyed at least $i$ months, given that one has been unemployed for at least $i-1$ months. We estimate these conditional probabilities from data on the duration of unemployment; 1 month, 1-3 month, 3-6 month, 6-12 month, 12-24 month and over 24 months using linear interpolation. ${ }^{13}$

Given the $p_{j}$, let $x_{i}=P i_{j=1}^{i} p_{j}$ be the probability of being unemployed for at least $j$ months, given that an unemployment spell has begun. Thus, $x_{i}$ is the probability that than an unemployment spell, once begun, will last at least i months. Then $z_{i}=x_{i}-x_{i+1}$ is the probability that an unemployment spell lasts exactly $i$ months, given that an unemployment spell has begun.

Then expected income in the first year of unemployment is calculated as $m=\sum_{j=1}^{11} z_{j} m_{j}+x_{12} m_{12}$ where $m_{j}$ is annual income for an individual with a duration spell of unemployment of exactly $\mathrm{j}$ periods. Thus a person with a duration of unemployment spell of one month has annual income of $0.65 / 12+11 / 12=m_{1}$ This defines the replacement ratio in our annual model. It is 0.842 in 1990 and 0.683 in 2000.

\footnotetext{
${ }^{13}$ The data source is Report on the Special Survey of the Labor Force Survey by the Statistics Bureau, Management and Coordination Agency, Government of Japan.
} 


\section{Transition probability matrix}

We model employment as a stationary, two-state, first-order Markov process with transition matrix of the form:

$$
\left[\begin{array}{ll}
\operatorname{Prob}\left(s_{1} \mid s_{1}\right) & \operatorname{Prob}\left(s_{2} \mid s_{1}\right) \\
\operatorname{Prob}\left(s_{1} \mid s_{2}\right) & \operatorname{Prob}\left(s_{2} \mid s_{2}\right)
\end{array}\right]=\left[\begin{array}{ll}
1-P_{0} & P_{0} \\
1-P_{1} & P_{1}
\end{array}\right]
$$

where $s_{1}$ means employed, $s_{2}$ means unemployed and $\operatorname{Prob}\left(s_{k} \mid s_{j}\right)$ is the conditional probability of being the state $s_{k}$ from the state $s_{j}$ for $j, k=1,2$. We measure $P_{1}$, the probability of being unemployed this year conditional on being unemployed last year, by $\prod_{j=1}^{13} p_{j}$, the probability that an unemployment spell, once begun, will last for at least 13 months. We use the unemployment rate, which is given by $\nu=(1-\nu) P_{0}+\nu P_{1}$, to measure the remaining transition probability $P_{0}$. The transition matrices for 1990 and 2000 are respectively given by:

$$
P^{1990}=\left[\begin{array}{ll}
0.981 & 0.019 \\
0.931 & 0.069
\end{array}\right], \quad P^{2000}=\left[\begin{array}{ll}
0.956 & 0.044 \\
0.836 & 0.164
\end{array}\right]
$$

\section{Demographic parameters}

The exogeneous demographic parameters consist of the initial population distribution $\mu_{1990}$, the fertility rate $n_{1, t}, t=1990, \ldots, 2000$, and the conditional surviving probability $\left\{\psi_{j}\right\}_{j=1}^{J}, t=1990, \ldots, 2000$. We have data on Population and Deaths for $t=1990, \ldots, 2001$ and for $j=1, \ldots, J$. ${ }^{14}$ Note that the model age $j=1$ means age 21 and $\mathrm{J}$ is set to 65 in our simulations. Then the maximum age is 85 , which is the maximum available age data in Population. This is the reason why we set $J=65$.

The initial population distribution $\mu_{1990}$ is given by the Japanese population distribution for 1990 in our steady-state analysis and the Japanese population distribution in 1985 in our dynamic analysis. The fertility rate and the conditional surviving probability are calculated as: for $t=1985, \ldots, 2000$

$$
\begin{aligned}
& n_{1, t}=\left(\text { Population }_{1, t+1}-\text { Population }_{1, t}\right) / \text { Population }_{1, t} \\
& \psi_{j, t}=1-\text { Dealth }_{j-1, t-1} / \text { Population }_{j-1, t-1}
\end{aligned}
$$

\footnotetext{
${ }^{14}$ The data source: Population is the Annual Report on Current Population Estimates by the Ministry of Public Management, Home Affairs, Posts and Telecommunications; Deaths are the Vital Statistics by the Ministry of Health, Labor and Welfare.
} 


\section{The other exogeneous parameters}

We follow Hayashi and Prescott(2002) in calibrating the other parameters with the exceptions of the time preference parameter $\beta$ and the relative risk aversion $\sigma$. The value of $\beta$ is chosen to reproduce the 1990 value of the after-tax real interest rate in the data. ${ }^{15}$ The values of the other parameters are as follows.

\begin{tabular}{cl}
\multicolumn{2}{c}{ Calibrated parameters } \\
\hline \hline$\alpha$ & 0.36 \\
$\beta$ & $0.97(0.98)$ \\
$\delta$ & 0.089 \\
$\tau$ & 0.48 \\
$\sigma$ & 2 \\
\hline
\end{tabular}

\section{A.2 Simulation Methodology}

\section{Stationary equilibrium}

Given data on conditional survival probabilities $\left\{\psi_{j}\right\}$ we next need to translate the economy into the economy with variables in per-capita efficiency units. Define a cohort share in total population by $\tilde{\mu}_{j}=\mu_{j} / N$. Then the stationary population distribution, cohort shares $\left\{\tilde{\mu}_{j}^{*}\right\}_{j=1}^{J}$ are calculated by $\tilde{\mu}_{j}^{*}=\psi_{j} \tilde{\mu}_{j-1}^{*} /\left(1+n_{1}\right)$ such that $\sum_{j} \tilde{\mu}_{j}^{*}=1$ holds. ${ }^{16}$ In a stationary equilibrium all variables in per-capita efficiency units are constant over time, so we can ignore the time subscript $t$. Then the transformed Bellman's equation is expressed as:

$$
V_{j}\left(\tilde{x}_{j}\right)=\max \left\{u\left(\tilde{c}_{j} / \eta_{j}\right)+\tilde{\beta} \psi_{j+1} \sum_{s_{j+1}} V\left(\tilde{x}_{j+1}\right) P\left(s_{j+1}, s_{j}\right)\right\}
$$

subject to

$$
\begin{aligned}
& \tilde{c}_{j}+\tilde{a}_{j}=R \tilde{a}_{j-1} / \gamma+\tilde{w} \epsilon_{j} s_{j}-\tilde{\theta}_{j}+m \tilde{w} \epsilon_{j}\left(1-s_{j}\right)+\tilde{\xi} \\
& a_{j, t} \geq 0, \quad c_{j, t} \geq 0
\end{aligned}
$$

\footnotetext{
${ }^{15}$ In the steady-state analysis the value of $\beta$ is set to 0.978 and in the dynamic analysis it is set to 0.985 .

${ }^{16}$ Note that we need only the conditional survival probabilities $\left\{\psi_{j}\right\}$ to calculate the stationary population distribution cohort shares. Next define $\mu_{j}=\Pi_{i=1}^{j} \psi_{i}$ as $\psi_{1}=1$ and $N=\sum_{j=1}^{J} \mu_{j}$. Then we can calculate $\left\{\tilde{\mu}_{j}^{*}\right\}$ as described above.
} 
where $\tilde{x}_{j}=\left\{\tilde{a}_{j-1}, s_{j}\right\}, \tilde{\beta}=\beta \gamma^{(1-\sigma)}$ and $R=1+r-\delta$. Since $\tilde{\theta}_{j}=\tau_{a}(R-$ 1) $\tilde{a}_{j-1} / \gamma$ by $(10)$, the budget constraint becomes:

$$
\tilde{c}_{j}+\tilde{a}_{j}=(1+\hat{r}) \tilde{a}_{j-1} / \gamma+\tilde{w} \epsilon_{j} s_{j}+m \tilde{w} \epsilon_{j}\left(1-s_{j}\right)+\tilde{\xi}
$$

where $\hat{r}=\left(1-\tau_{a}\right)(r-\delta)$ is the equilibrium after-tax real interest rate.

Let $\epsilon_{1}>0$ and $\epsilon_{2}>0$ denote the convergence criteria for the aftertax real interest rate and lump-sum transfers in per-capita efficiency units, respectively. Computing a stationary equilibrium requires finding a fixed point in the after-tax real interest rate, $\hat{r}^{*}$, and the lump-sum transfers in per-capita efficiency units, $\tilde{\xi}^{*}$. This is accomplished in the following way. First set the smoothing parameter $\rho \in(0,1)$ and guess $\hat{r}_{0}$ and $\tilde{\xi}_{0}$. Then iterate on the following steps:

1. Compute the average efficiency of labor input $h=(1-\nu) \sum_{j=1}^{J_{r}-1} \tilde{\mu}_{j}^{*} \epsilon_{j}$ and the real wage in efficiency unit $\tilde{w}_{0}$ using the first-order condition of the firms maximization problem.

2. Compute the decision rules $\left\{\tilde{a}_{j}\left(\tilde{x}_{j}\right), \tilde{c}_{j}\left(\tilde{x}_{j}\right)\right\}_{j=1}^{J}$ by completing a backward induction from the age $J$ to the age 1 with the terminal condtion $a_{J}=0$, and the wealth distribution $\lambda=\left\{\lambda_{j}\left(\tilde{x}_{j}\right)\right\}_{j=1}^{J}$ by completing a forward recursion from the age 1 to the age $J$ with the initial condtion (16).

3. Compute the new capital stock in per-capita efficiency unit using the law of motion for capital $\tilde{k}=\sum_{j} \sum_{a} \sum_{s} a_{j}\left(\tilde{x}_{j}\right) \lambda_{j}\left(\tilde{x}_{j}\right) \tilde{\mu}_{j}^{*} /$ gamma and derive the new after-tax real interest rate, $\hat{r}_{1}$, from the above $\tilde{k}$ using the first-order condition of the firms profit maximization problem. Next compute the new lump-sum transfers in per-capita efficiency unit. By transforming the equations (17),(18) and (20) into the per-capita efficiency unit form we have

$$
\tilde{\xi}_{1}=\tilde{b}+\tilde{t t}-\sum_{j} \sum_{a} m \tilde{w} \epsilon_{j} \lambda_{j}\left(\tilde{x}_{j}\right) \tilde{\mu}_{j}^{*}
$$

where ${ }^{17}$

$$
\tilde{b}=\sum_{j} \sum_{a} \sum_{s}\left(1-\psi_{j}\right) R_{0} \tilde{a}_{j-1}\left(\tilde{x}_{j-1}\right) \lambda\left(\tilde{x}_{j-1}\right) \tilde{\mu}_{j-1}^{*}
$$

\footnotetext{
${ }^{17}$ Since the subscript $t$ is used for indicating time, we define the per capita capital income $\operatorname{tax}$ as $t t=T / N$.
} 


$$
\begin{aligned}
\tilde{t t} & =\sum_{j} \sum_{a} \sum_{s}\left(1-\psi_{j}\right) \tilde{\theta}_{j}\left(\tilde{x}_{j-1}\right) \lambda_{j-1}\left(\tilde{x}_{j-1}\right) \tilde{\mu}_{j-1}^{*} \\
R_{0} & =1+\hat{r}_{0} /\left(1-\tau_{a}\right)
\end{aligned}
$$

4. If $\left|\hat{r}_{1}-\hat{r}_{0}\right| /\left|\hat{r}_{0}\right|<\epsilon_{1}$ and $\left|\tilde{\xi}_{1}-\tilde{\xi}_{0}\right| /\left|\tilde{\xi}_{0}\right|<\epsilon_{2}$, stop. Then we have got the equilibrium: $\hat{r}^{*}=\hat{r}_{0}$ and $\tilde{\xi}^{*}=\tilde{\xi}_{0}$. If not, compute $\hat{r}_{2}=\rho \hat{r}_{0}+(1-\rho) \hat{r}_{1}$ and $\tilde{\xi}_{2}=\rho \tilde{\xi}_{0}+(1-\rho) \tilde{\xi}_{1}$. Set $\hat{r}_{0}=\hat{r}_{2}$ and $\tilde{\xi}_{0}=\tilde{\xi}_{2}$, and go to step 1 .

\section{Transitional dynamics without unemployment risk}

Assume that the economy starts from the period $t=1$. Agents have all the information available at the end of $t=0$. The agents have perfect foresight about the entire future paths of total factor productivity, $\left\{A_{t}\right\}_{t=1}^{\infty}$, of the government policies, $\left\{\Psi_{t}\right\}_{t=1}^{\infty}$, and of the demographics $\left\{\Gamma_{t}\right\}_{t=1}^{\infty}$. Note that there is no employment risk. The individual state is simply $\tilde{x}_{j, t}=\left\{\tilde{a}_{j-1, t-1}\right\}$. The transformed Bellman's equation is:

$$
\begin{aligned}
& V_{j, t}\left(\tilde{x}_{j, t} ; X_{t}, \Psi^{t}\right) \\
= & \max \left\{u\left(\tilde{c}_{j, t} / \eta_{j}\right)+\tilde{\beta}_{t} \psi_{j+1} V_{j+1, t+1}\left(\tilde{x}_{j+1, t+1} ; X_{t+1}, \Psi^{t}\right)\right\}
\end{aligned}
$$

subject to

$$
\begin{aligned}
& \tilde{c}_{j, t}+\tilde{a}_{j, t}=R_{t} \tilde{a}_{j-1, t-1} / \gamma_{t-1}+\tilde{w}_{t} \epsilon_{j}-\tilde{\theta}_{j, t}+\tilde{\xi}_{t} \\
& \tilde{a}_{j, t} \geq 0, \quad \tilde{c}_{j, t} \geq 0 \\
& \tilde{\mu}_{t+1}=\mu_{t+1} / N_{t+1}, \quad N_{t+1}=\sum_{j} \mu_{t+1}, \quad \mu_{t+1}=\Gamma_{t} \mu_{t}
\end{aligned}
$$

and the law of motion for the per-capita-efficiency-unit wealth distribution, and the law of motion for the capital stock in per-capita efficiency unit. We will derive an equilibrium transition path from the initial condition to the final stationary equilibrium. Computing the equilibrium transition path requires finding paths of the after-tax real interest rate, $\left\{\hat{r}_{t}^{*}\right\}_{t=1}^{\infty}$, and of the lump-sum transfers in per-capita efficiency units. $\left\{\tilde{\xi}_{t}^{*}\right\}_{t=1}^{\infty}$, This is done using the following steps. First set $\epsilon_{1}, \epsilon_{2}>0$ and $\rho \in(0,1)$. 
1. Set the initial conditions $\left\{a_{j, 0}\right\}_{j=1}^{J}, \gamma_{0}$ and $\mu_{1}$. ${ }^{18}$ Next set $\left\{\gamma_{t}, \Psi_{t}, \Gamma_{t}\right\}_{t=1}^{\infty}$ such that for $t_{1}<\infty$ we have $\left\{\gamma_{t}, \Psi_{t}, \Gamma_{t}\right\}=\left\{\gamma_{t_{1}}, \Psi_{t_{1}}, \Gamma_{t_{1}}\right\}$ for all $t \geq t_{1}$. Compute the final stationary equilibrium, $\hat{r}^{* *}$ and $\tilde{\xi}^{* *}$, assuming that $\{\gamma, \Psi, \Gamma\}=\left\{\gamma_{t_{1}}, \Psi_{t_{1}}, \Gamma_{t_{1}}\right\}$

2. Guess the paths of the after-tax real interest rate and the lump-sum transfers in per-capita efficiency units $\left\{\hat{r}_{0, t}, \tilde{\xi}_{0, t}\right\}_{t=1}^{\infty}$ such that $\left\{\hat{r}_{0, t}, \tilde{\xi}_{0, t}\right\}=$ $\left\{\hat{r}^{* *}, \tilde{\xi}^{* *}\right\}$ for all $t \geq T$ where $T$ is sufficiently large that we are close to the final stationary equilibrium, say, $T=t_{1}+130$.

3. Compute the paths of the average efficiency of labor input $\left\{h_{t}\right\}_{t=1}^{T}$ where $h_{t}=\sum_{j=1}^{J_{r}-1} \tilde{\mu}_{j}^{*} \epsilon_{j}$ and of the real wage in efficiency units $\left\{\tilde{w}_{0, t}\right\}_{j=1}^{T}$ using the first-order condtion of the firms maximization problem.

4. Compute the decision rules of the households alive at $t=1$ and derive the path of life-time asset holdings, $\left\{a_{J-i+t, t}\right\}_{t=1}^{i}$ for $i=1,2, . ., J$ using the initial conditions $\left\{a_{j, 0}\right\}_{j=1}^{J}$ where $i$ denote the maximum life-time period left for each household alive at $t=1$. Compute the decision rules for the household born at $t=2,3, \ldots, T$ and derive the path of life-time asset holdings, $\left\{a_{j, j+t-1}\right\}_{j=1}^{J}$ for $t=2,3, \ldots, T$ using the initial asset holdings $\tilde{a}_{0, t}=0$ for all $t$.

5. Compute the capital stock in per-capita efficiency unit

$\tilde{k}_{t}$ $\sum_{j=1}^{J} \tilde{a}_{t-1, j-1} \tilde{\mu}_{j-1, t-1} / \gamma_{t-1}$ and derive the new after-tax real intrest rate, $\hat{r}_{1, t}$ for all $t=1,2, \ldots, T$. Next compute the new lump-sum transfers in percapita efficiency unit $\tilde{\xi}_{1, t}=\tilde{b}_{t}+\tilde{t t}_{t}$ for all $t=1,2, \ldots, T$ where

$\tilde{b}_{t+1}=\sum_{j}\left(1-\psi_{j+1, t+1}\right) R_{0, t+1} \tilde{a}_{j, t} \tilde{\mu}_{j, t}, \tilde{t t}_{t+1}=\sum_{j}\left(1-\psi_{j+1, t+1}\right) \tilde{\theta}_{j+1, t+1} \tilde{\mu}_{j, t}$

6. If $\sum_{t=1}^{T}\left|\hat{r}_{1, t}-\hat{r}_{0, t}\right| /\left|\hat{r}_{0, t}\right|<\epsilon_{1}$ and $\sum_{t=1}^{T}\left|\tilde{\xi}_{1, t}-\tilde{\xi}_{0, t}\right| /\left|\tilde{\xi}_{0, t}\right|<\epsilon_{2}$, stop. Then we have got the equilibrium transition path $\hat{r}_{t}^{*}=\hat{r}_{0, t}$ and $\tilde{\xi}_{t}^{*}=\tilde{\xi}_{0, t}$ for all $t=1,2, \ldots, T$. Otherwise, compute $\hat{r}_{2, t}=\rho \hat{r}_{0, t}+(1-\rho) \hat{r}_{1, t}$ and $\tilde{\xi}_{2, t}=\rho \tilde{\xi}_{0, t}+(1-\rho) \tilde{\xi}_{1, t}$ for all $t=1,2, \ldots, T$. Set $\hat{r}_{0, t}=\hat{r}_{2, t}$ and $\tilde{\xi}_{0, t}=\tilde{\xi}_{2, t}$ for all $t=1,2, \ldots, T$ and go back to step 3 .

\footnotetext{
${ }^{18}$ These values are obtained directly from the data or by computing the initial stationary equilibrium assuming some conditions.
} 


\section{References}

[1] Aiyagari, S.Rao (1994) "Uninsured Idiosyncratic Risk and Aggregate Saving", Quarterly Journal of Economics, 109,3,659-684

[2] Cubeddu, L.M., and Rios Rull, J.-V.(1996) "Martial Risk and Capital Accumulation", Mimeo, University of Pennsylvania.

[3] Hansen, G.D.(1993) "The Cyclical and Secular Behavior of the Labor Input: Comparing Efficiency Units and Hours Worked", Journal of Applied Econometrics, 8, 71-80

[4] Hayashi, F. (1995) "Is the Japanese extended family altristic link? The test based on Engel curve.", Journal of Political Economy, 3, 661-674

[5] Hayashi, F. (1997) "Understanding Saving", MIT Press

[6] Hayashi, F.,Ito, T. and Slemrod, J.(1988) "Housing Finance Imperfections, Taxation, and Privates Saving:A Comparative Simulation Analysis of the United States and Japan", Journal of the Japanese and International economies, 2, 215-238.

[7] Hayashi, F., and Prescott, E.C.(2002) "The 1990s in Japan: A Lost Decade", Review of Economic Dynamics, 5, 206-35.

[8] Horioka, C. Y.(1990) "Why is Japan's Household's Saving Rate So High?", Journal of the Japanese and International Economies, 4, 4992

[9] Horioka, C. Y., Fujisaki, H., Watanabe, W.and Kouno, T. (2000) "Are Americans More Altrustic than the Japanese? A.U.S-Japan Comparison of Saving and Bequest Motives", NBER Working paper 7463

[10] Iiduka, N (2003) "Did the Japanese Saving Ratio Decline Sharply in 2000-2001 in terms of the actual economy?", Mimeo, Japan Center for Economic Reserch

[11] Modigliani,F. and Brumberg, R. (1954) "Utility Analysis and the Consumption Function: An Interpretation of Cross-Section Data", in Kenneth K. Kurihara, ed., Post Keynesian Economics (New Brunswick, N.J., USA: Rutgers University Press), pp.388-436 
[12] Nishiyama, S. (2002) "Simulating Social Security Reform in a Stochastic OLG Economy with Heterogeneous agents.", Mimeo, Congressional Budget Office(November)

[13] Rios-Rull, J.-V. (2001) "Population Changes and Capital Accumulation: The Ageing of the Baby Boom", Mimeo, University of Pennsylvania. 
Figure 1

Demographic projections: model and IPSS

The fraction of age cohort 21-35 to total population

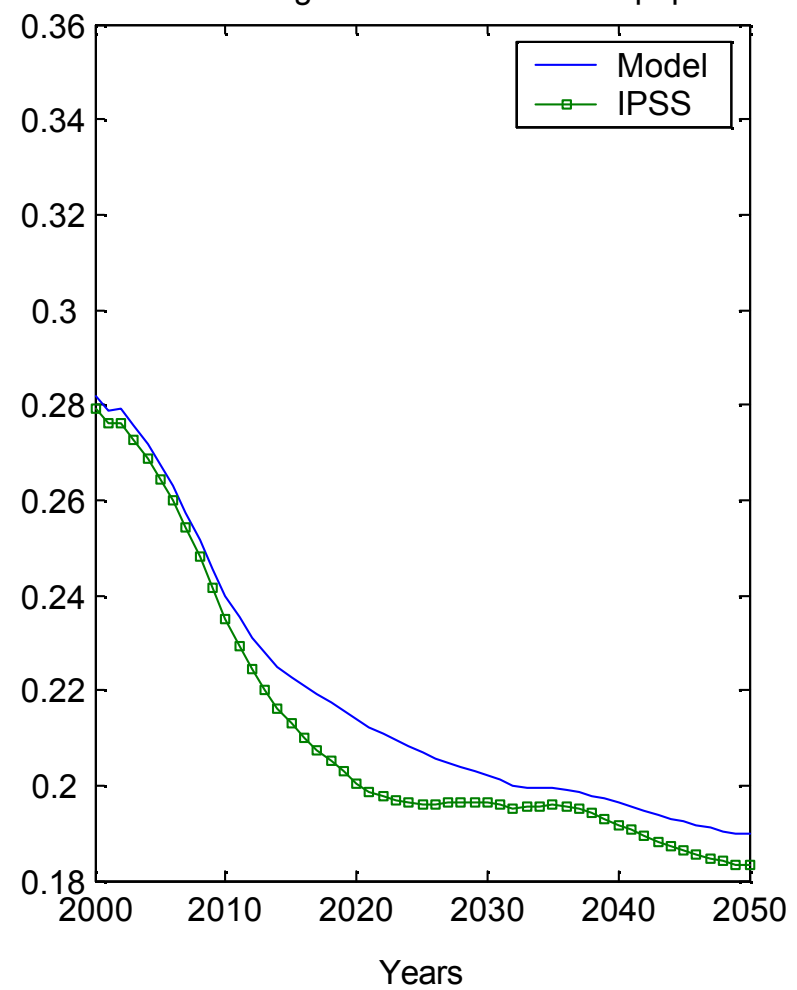

The fraction of age cohort 51-65 to total population

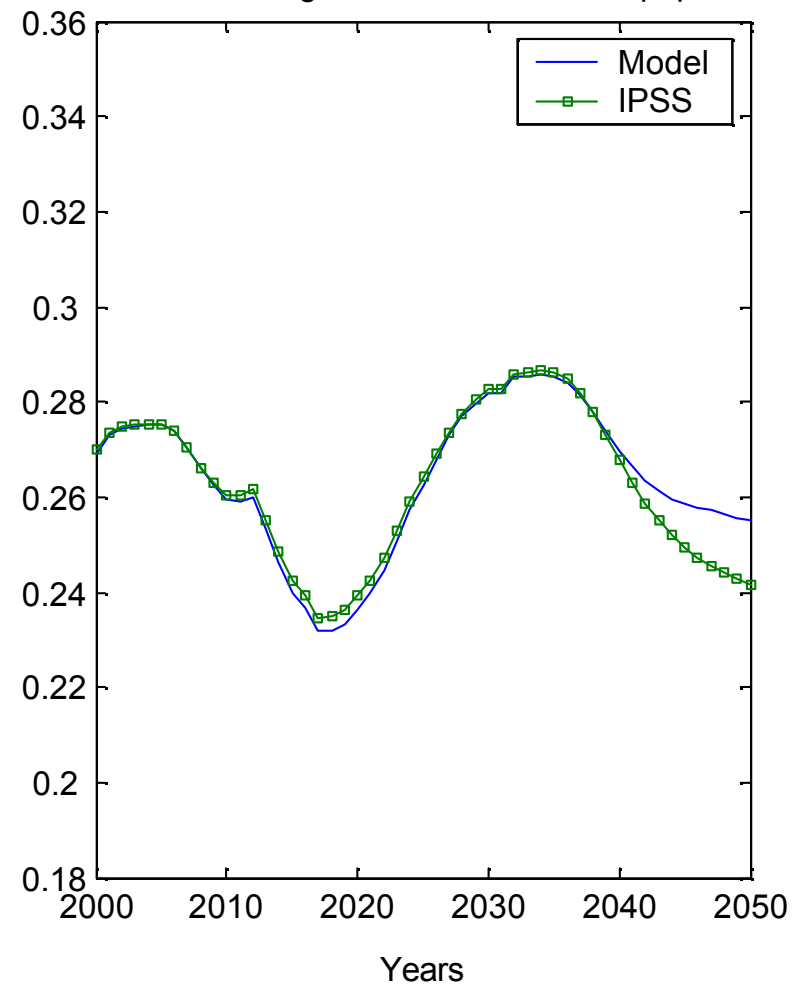

The fraction of age cohort 36-50 to total population

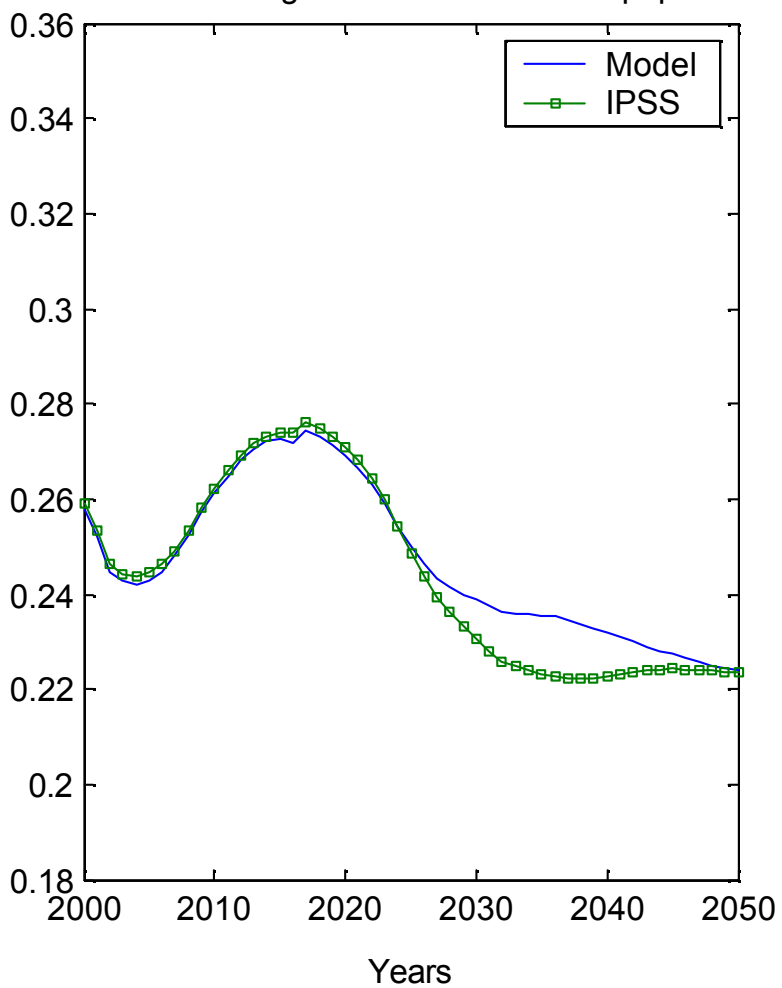

The fraction of age cohort 66-85 to total population

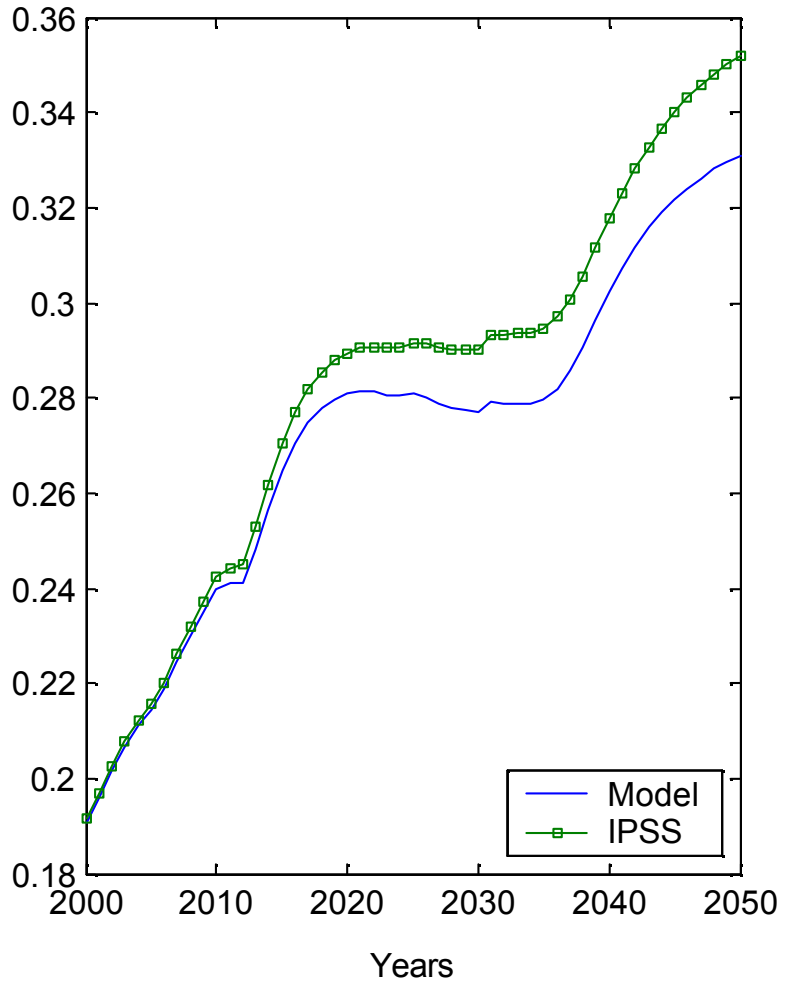


Figure 2

The evolution of the demographic structure
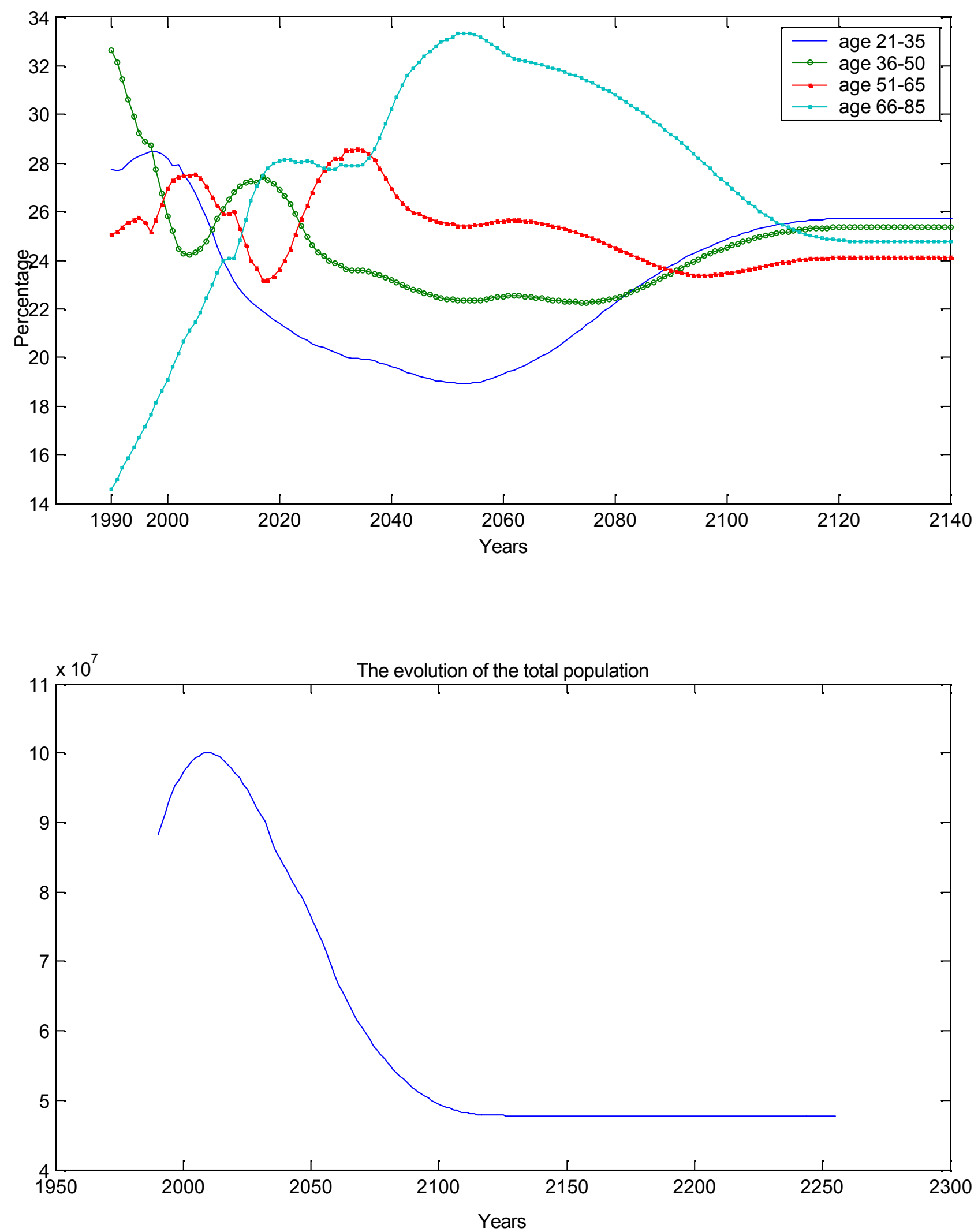
Figure 3

Baseline Specification and Japanese Data

The evolution of the after-tax real interest rate: 1990-2005

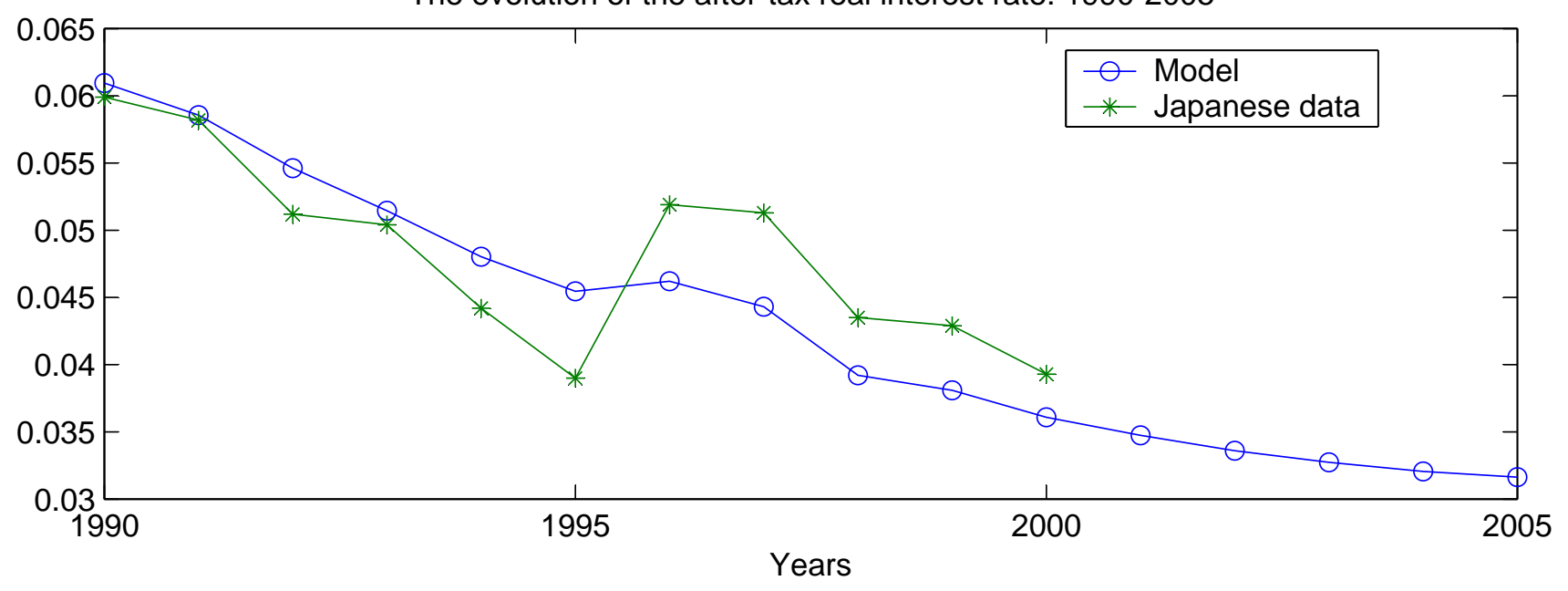

The evolution of national saving: 1990-2005

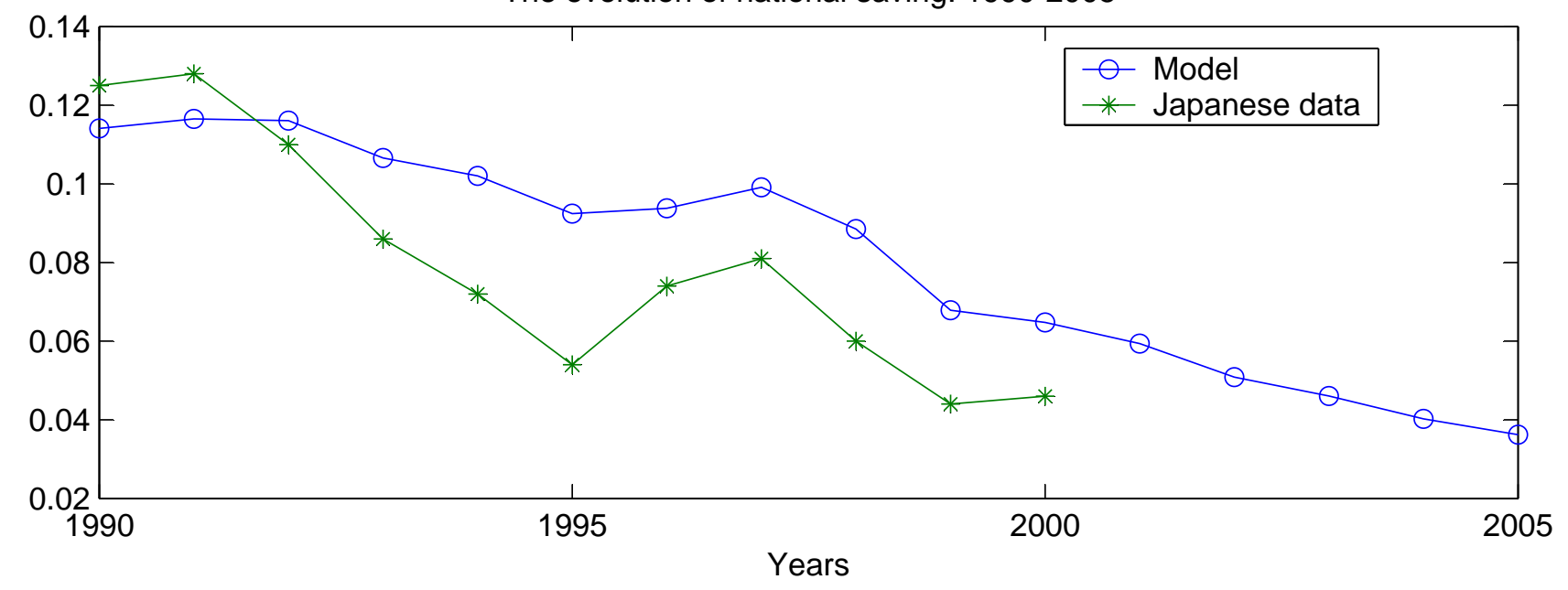


Long-Run Implications of Baseline Specification

The evolution of the after-tax real interest rate: 1990-2140

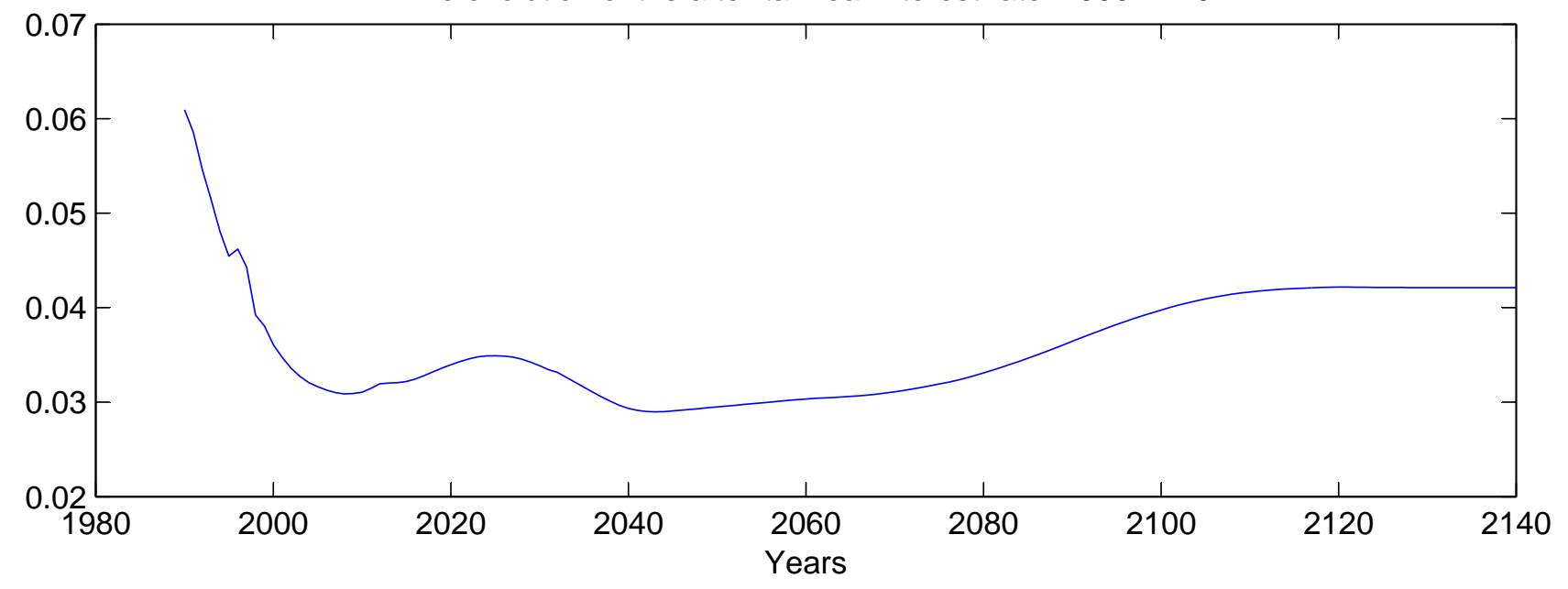

The evolution of private sector saving: $1990-2140$

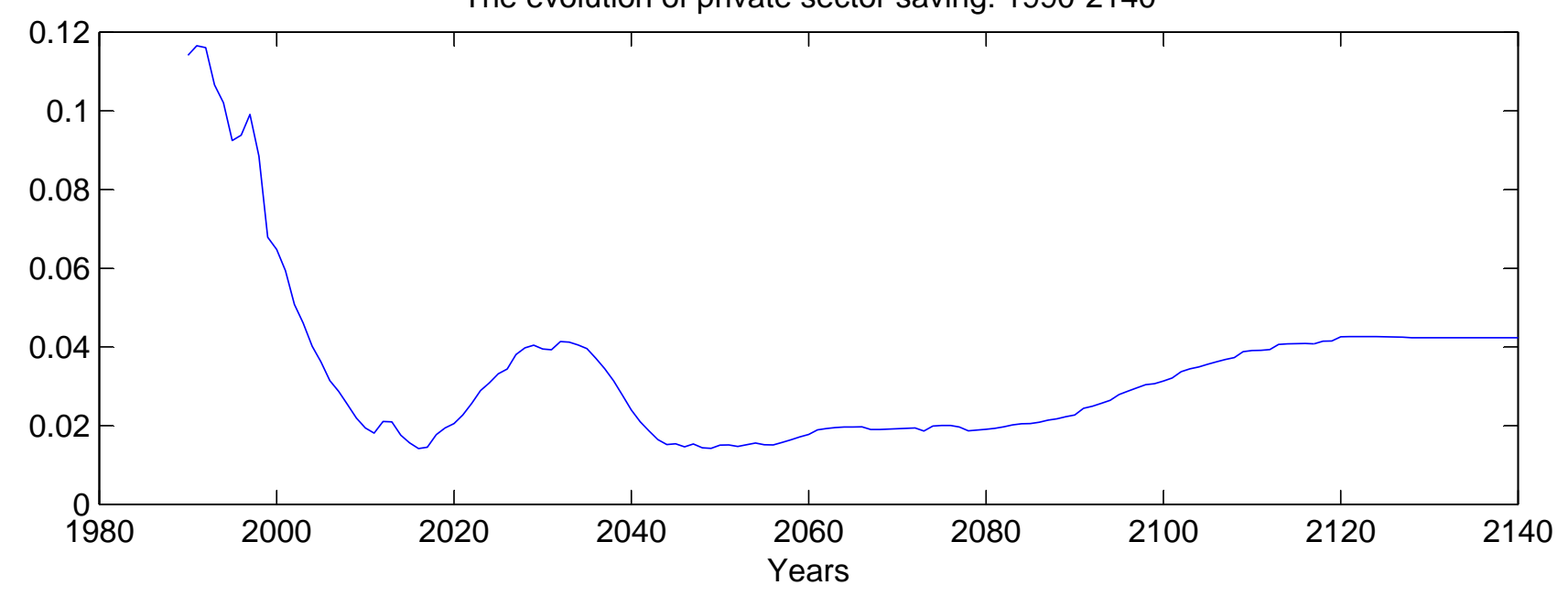


Figure 5

Assessing the Contribution of Demographics and TFP

The evolution of the after-tax real interest rate: 1990-2140

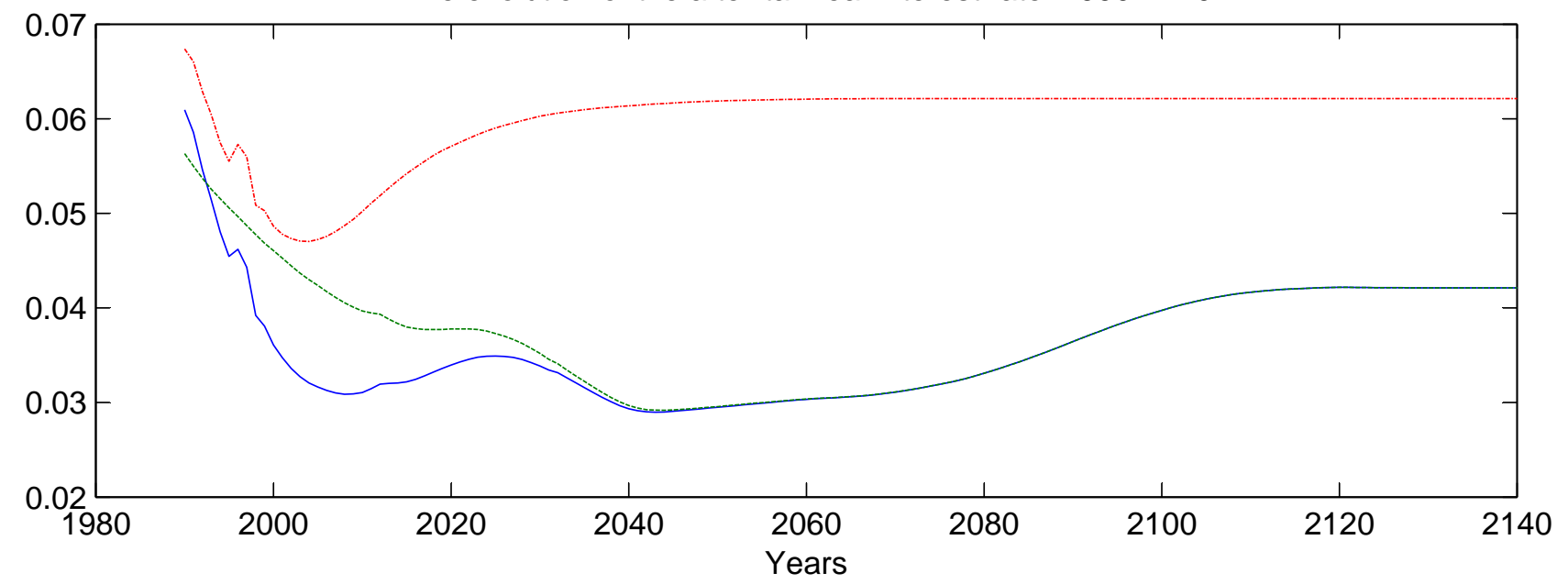

The evolution of private sector saving: $1990-2140$

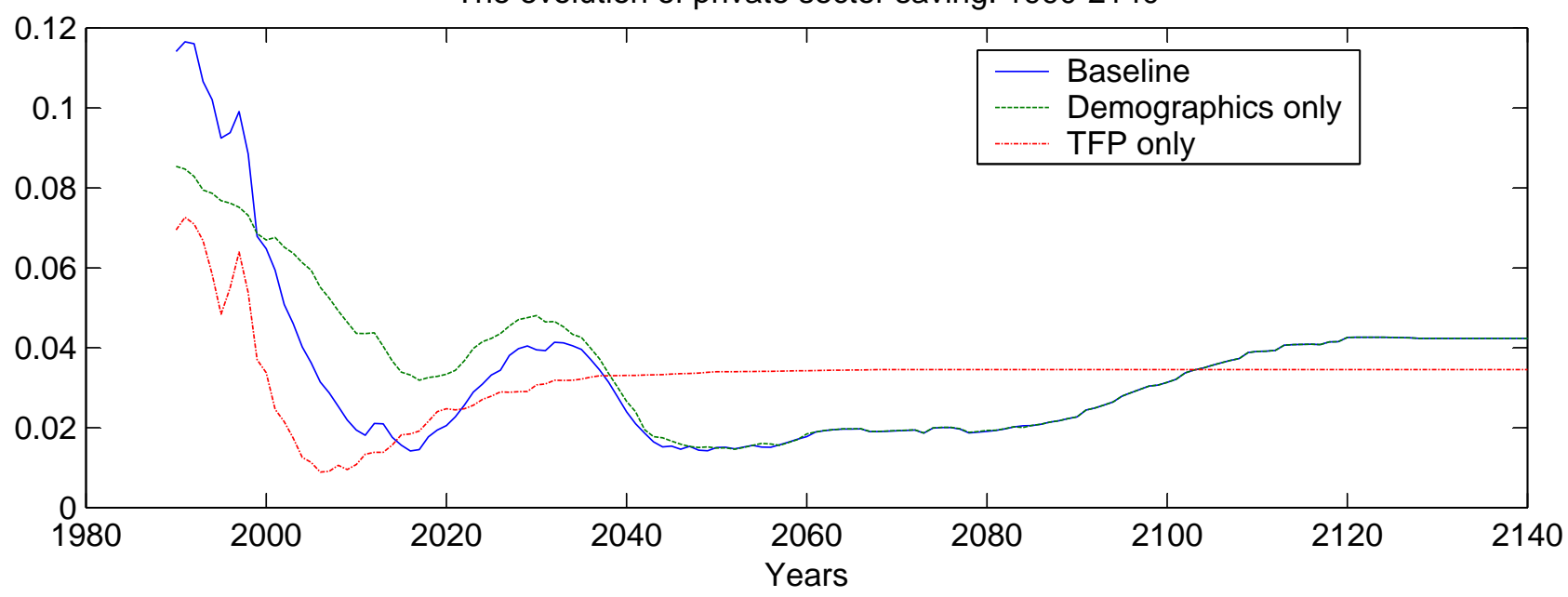


Figure 6

Permanently Low TFP and Baseline Specifications

The evolution of the after-tax real interest rate: 1990-2140

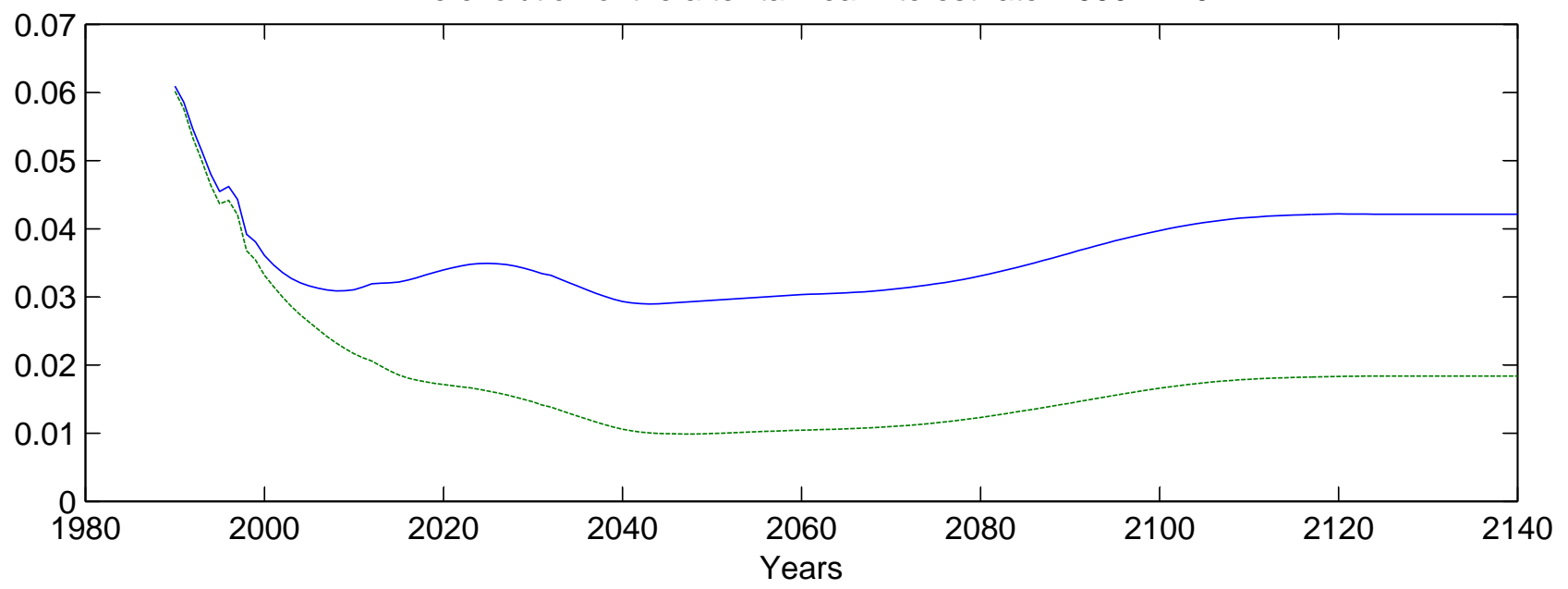

The evolution of private sector saving: 1990-2140

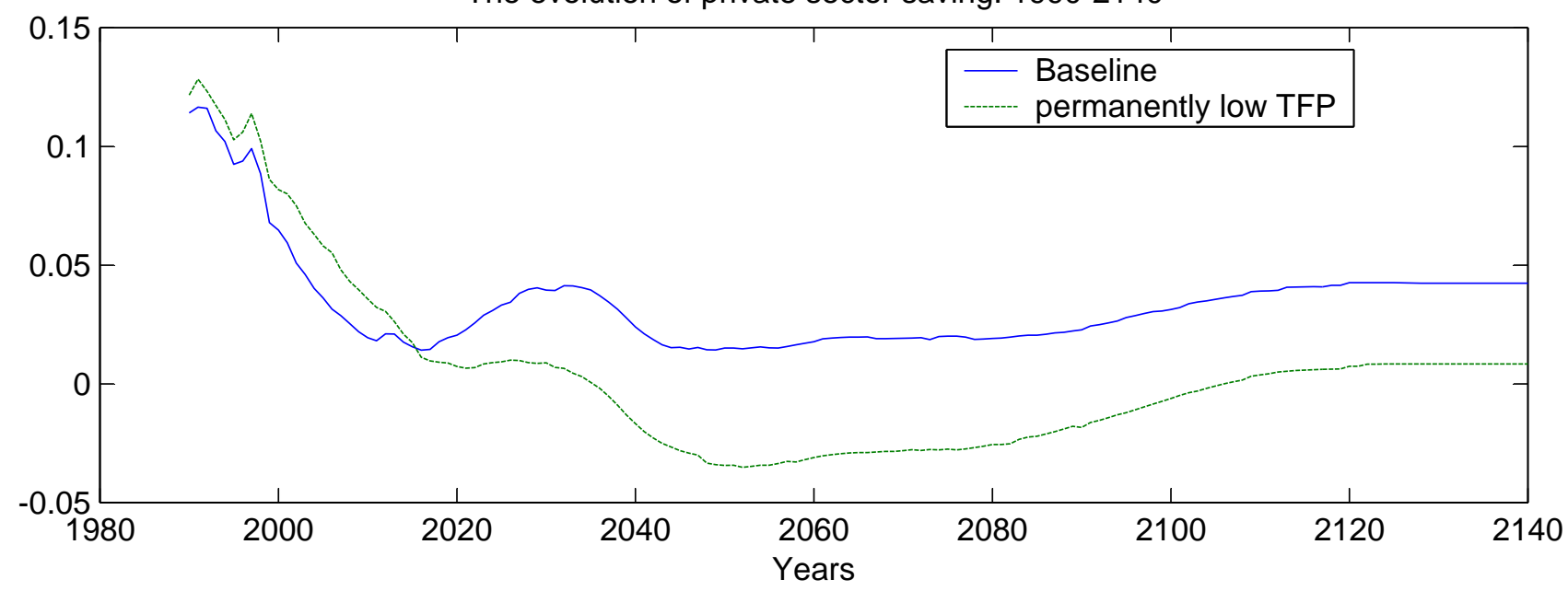

